\title{
Object-Based Inversion of Crosswell Radar Tomography Data to Monitor Vegetable Oil Injection Experiments
}

\author{
John W. Lane, Jr., U.S. Geological Survey, Storrs, CT \\ Frederick D. Day-Lewis, Bucknell University, Lewisburg, PA \\ Roelof J. Versteeg, Idaho National Environmental and Engineering Laboratory, Idaho Falls, ID \\ Clifton C. Casey, Southern Division NAVFAC, North Charleston, SC
}

\begin{abstract}
Crosswell radar tomography methods can be used to dynamically image ground-water flow and mass transport associated with tracer tests, hydraulic tests, and natural physical processes. Dynamic imaging can be used to identify preferential flow paths and to help characterize complex aquifer heterogeneity. Unfortunately, because the raypath coverage of the interwell region is limited by the borehole geometry, the tomographic inverse problem is typically underdetermined, and tomograms may contain artifacts such as spurious blurring or streaking that confuse interpretation.

We implement object-based inversion (using a constrained, non-linear, least-squares algorithm) as an alternative to pixel-based inversion approaches that utilize regularization (such as damping or smoothing criteria). Our approach requires pre- and post-injection travel-time data. Parameterization of the image plane comprises a small number of objects rather than a large number of pixels, resulting in an overdetermined problem that reduces the need for prior information. The nature and geometry of the objects are based on hydrologic insight into aquifer characteristics, the nature of the experiment, and the planned use of the geophysical results.

The object-based inversion approach is demonstrated using synthetic and crosswell radar field data acquired during vegetable-oil injection experiments at a site in Fridley, Minnesota. The region where oil has displaced ground water is discretized as a stack of rectangles of variable horizontal extents. The inversion provides the geometry of the affected region and an estimate of the radar slowness change for each rectangle. Applying petrophysical models to these results and porosity from neutron logs, we estimate that the vegetable-oil emulsion saturation in various layers ranges from 60 to $90 \%$. Further work is needed to assess the accuracy of the emulsion saturation estimates.

Using synthetic- and field-data examples, the object-based inversion approach is shown to be an effective strategy for inverting crosswell radar tomography data acquired to monitor the emplacement of vegetable-oil emulsions. A principal advantage of object-based inversion is that it yields images that hydrologists and engineers can easily interpret and use for model calibration.
\end{abstract}

\section{Introduction}

Subsurface injection of vegetable oil and (or) emulsions of vegetable oil and water is an in-situ biostimulation technique to enhance bioremediation at sites contaminated with volatile 
organic compounds (VOCs) (Fredrickson and others, 1993; Hutter and others, 1994). Vegetable oil serves as a substrate to the naturally existing microbial community to transform VOCs by oxidation-reduction reactions into carbon dioxide, water, and chloride. However, for this process to occur, the vegetable oil must be located in close contact with the contaminant and in sufficient quantity to maintain bioremediation. New field procedures capable of characterizing the spatial and temporal distribution and saturation of oil/water emulsions are needed to aid engineers and hydrologists in designing and implementing vegetable-oil biostimulation projects.

Crosswell radar difference tomography is an established method for dynamic imaging of ground-water flow and mass transport associated with tracer tests, hydraulic tests, and natural physical processes. Crosswell radar tomography methods have been used with tracers to identify permeable fractures and fracture zones in igneous and metamorphic rocks (Ramirez and Lytle, 1986; Niva and others, 1988; Olsson and others, 1992; Lane and others, 1996; Wright and others, 1996; Lane and others, 2000; Day-Lewis and others, in review), to identify flow paths in dualporosity media (Lane and others, 1998), and unconsolidated sediments (Kong and others, 1994; Hubbard and others, 2001), and have been used to monitor unsaturated zone recharge (Binley and others, 2001).

The travel-time of high-frequency electromagnetic (EM) waves between a transmitter and receiver is a function of EM (radar) propagation velocity, which in turn is a strong function of dielectric permittivity:

$$
t=\int_{R} \frac{1}{v(r)} d r=\int_{R} s(r) d r,
$$

where

$\mathrm{t}$ is travel-time $(\mu \mathrm{s})$;

$v$ is radar wave velocity $(\mathrm{m} / \mu \mathrm{s})$, and $v \approx \frac{c}{\sqrt{\varepsilon}_{r}}$;

$\mathrm{r}$ is the location along raypath $\mathrm{R}$ between the transmitter and receiver $(\mathrm{m})$;

$\mathrm{s}$ is the radar slowness, the inverse of velocity $(\mu \mathrm{s} / \mathrm{m})$;

$c$ is the velocity of electromagnetic waves in a vacuum $(299.79 \mathrm{~m} / \mu \mathrm{s})$; and

$\varepsilon_{r}$ is the dielectric permittivity of the medium, relative to a vacuum (dimensionless).

In difference travel-time tomography, the difference between pre- and post-injection travel-time measurements $(\Delta \mathrm{t})$ is modeled as a function of the change in radar slowness $(\Delta \mathrm{s})$ integrated along the raypath:

$$
\Delta t=\int_{R} \Delta s(r) d r
$$

The efficacy of crosswell radar travel-time or travel-time difference tomography relies on contrasts in relative dielectric permittivity between the target anomaly and background medium. The relative dielectric permittivity of vegetable oils is much lower than that of water $\left(\varepsilon_{r}^{\text {oil }} \sim 2.9\right.$ $\left.3.5 ; \varepsilon_{r}^{H_{2} O} \sim 80\right)$. We illustrate the effects of vegetable-oil emulsion injection on EM wave propagation velocity, using the low-loss simplification of the complex refractive index method (CRIM) for two- and three-phase mixtures (Birchak and others, 1974; Wharton and others, 
1980). Using CRIM, we estimate (1) the relative permittivity of vegetable-oil emulsions for a range of water/oil ratios (fig. 1); (2) the EM velocity through low-loss quartz sand ( $\varepsilon_{r}^{\text {quartz }} \sim 4.5$ ) containing emulsions of vegetable oil with a range of water content as a function of porosity (fig. 2); and (3) the slowness-difference anomaly that would result from injection of a vegetableoil emulsion containing $35 \%$ oil and $65 \%$ water into water-saturated quartz sand for different levels of emulsion pore space fluid displacement (emulsion saturation) (fig. 3). Based on the simple petrophysical modeling results, we expect injection of vegetable-oil emulsions into saturated porous media to significantly increase the propagation velocity of high-frequency EM waves traversing regions containing oil relative to background (pre-injection) measurements, and we propose the use of crosswell radar difference travel-time tomography to image velocity anomalies induced by vegetable-oil injection into porous media.

Traditionally, crosswell data are inverted using pixel-based methods such as the simultaneous iterative reconstruction technique to produce tomograms of slowness or attenuation. Unfortunately, in most field studies the raypath coverage of the inter-well region and acquisition of high-angle rays is severely limited by the borehole geometry. Limited angular aperture, low ray density, and measurement error lead to underdetermined tomographic inverse problems. Inverted tomograms can contain inversion artifacts such as spurious blurring or streaking. To suppress artifacts, regularization (such as damping or smoothness criteria) is applied; however, regularization may affect anomaly localization and parameter resolution and thereby inhibit or preclude quantitative assessment of the tomograms (Lane and others, 2000).

In this paper, an object-based inversion (OBI) approach is used to image the slowness anomalies induced by subsurface injection of vegetable-oil emulsions. Using OBI, the region where oil has displaced ground water is discretized as a stack of rectangles of variable horizontal extents, consistent with a conceptual hydrologic model of vegetable-oil emulsion displacement of water. The inversion parameters include the slowness difference values, the lateral extents of the rectangles, and the top and bottom elevations of the region affected by oil injection. OBI parameterization of the image plane comprises a small number of objects rather than a large number of pixels. This parsimonious parameterization results in an overdetermined inverse problem that reduces the need for prior information and produces tomograms readily interpreted by hydrologists and engineers. The potential advantages of the OBI approach are demonstrated through synthetic examples and by application to crosswell radar field data acquired in support of a pilot-scale vegetable-oil biostimulation project underway in the vicinity of the Naval Industrial Reserve Ordnance Plant (NIROP), in Fridley, Minnesota.

\section{Synthetic Model Experiments}

Synthetic models were developed to illustrate some of the limitations of pixel-based tomographic inversion methods identified by other investigators (McMechan,1983; Menke,1984) and the potential advantages of the OBI approach for imaging vegetable-oil emulsions in saturated porous media. The models were constructed assuming the tomographic image plane would include the injection borehole, located at the right side of the tomogram (fig. 4). The geometry of the target anomalies was designed to simulate post-injection oil distribution in the image plane (fig. 5). Three models of anomaly geometry are considered. Model 1 (fig. 5a) assumes simple cylindrical penetration of oil about the injection zone; models 2 and 3 (fig. 5b 


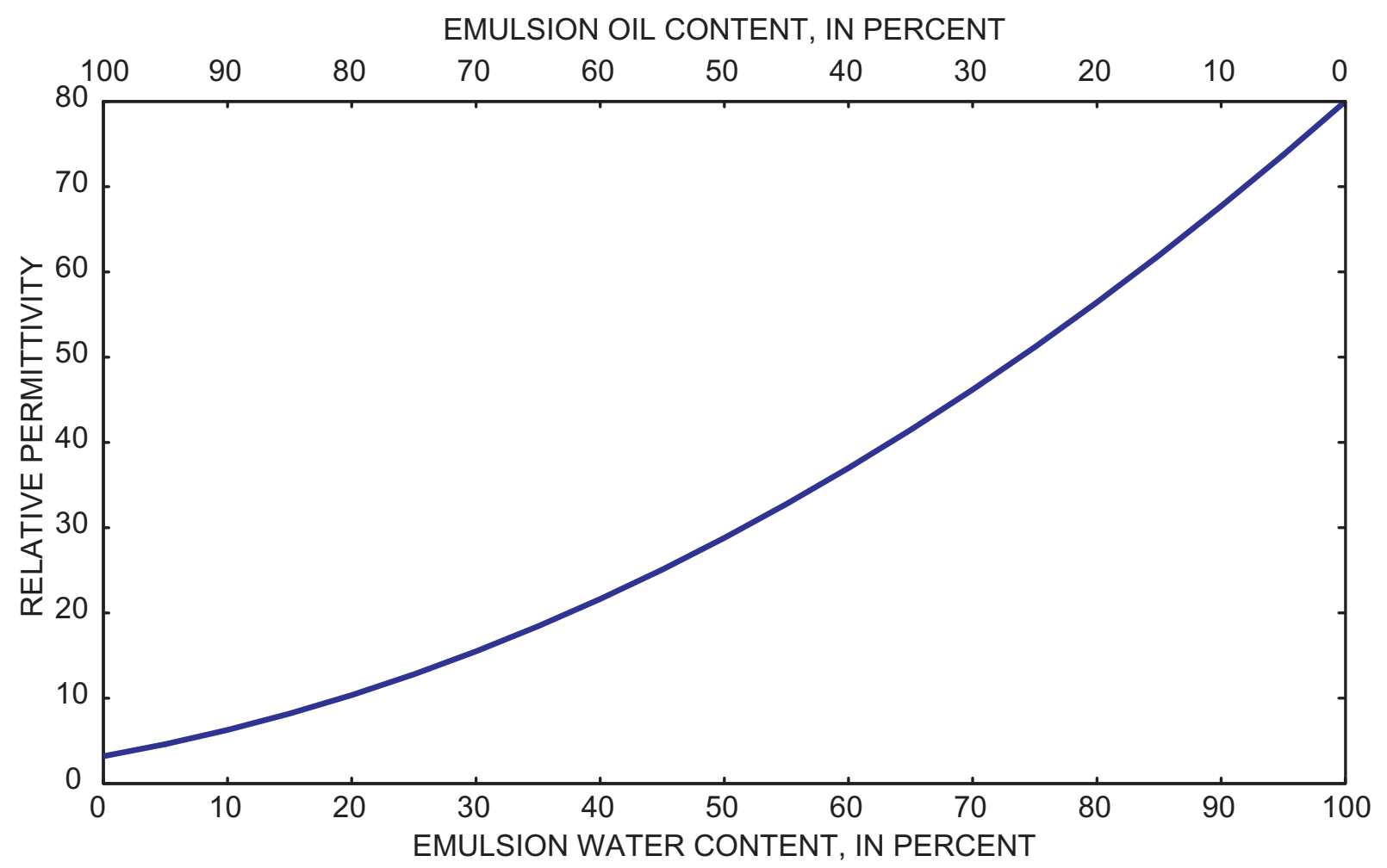

Figure 1. Relative permittivity of vegetable oil emulsions plotted against emulsion water content predicted by the complex refractive index method (CRIM).

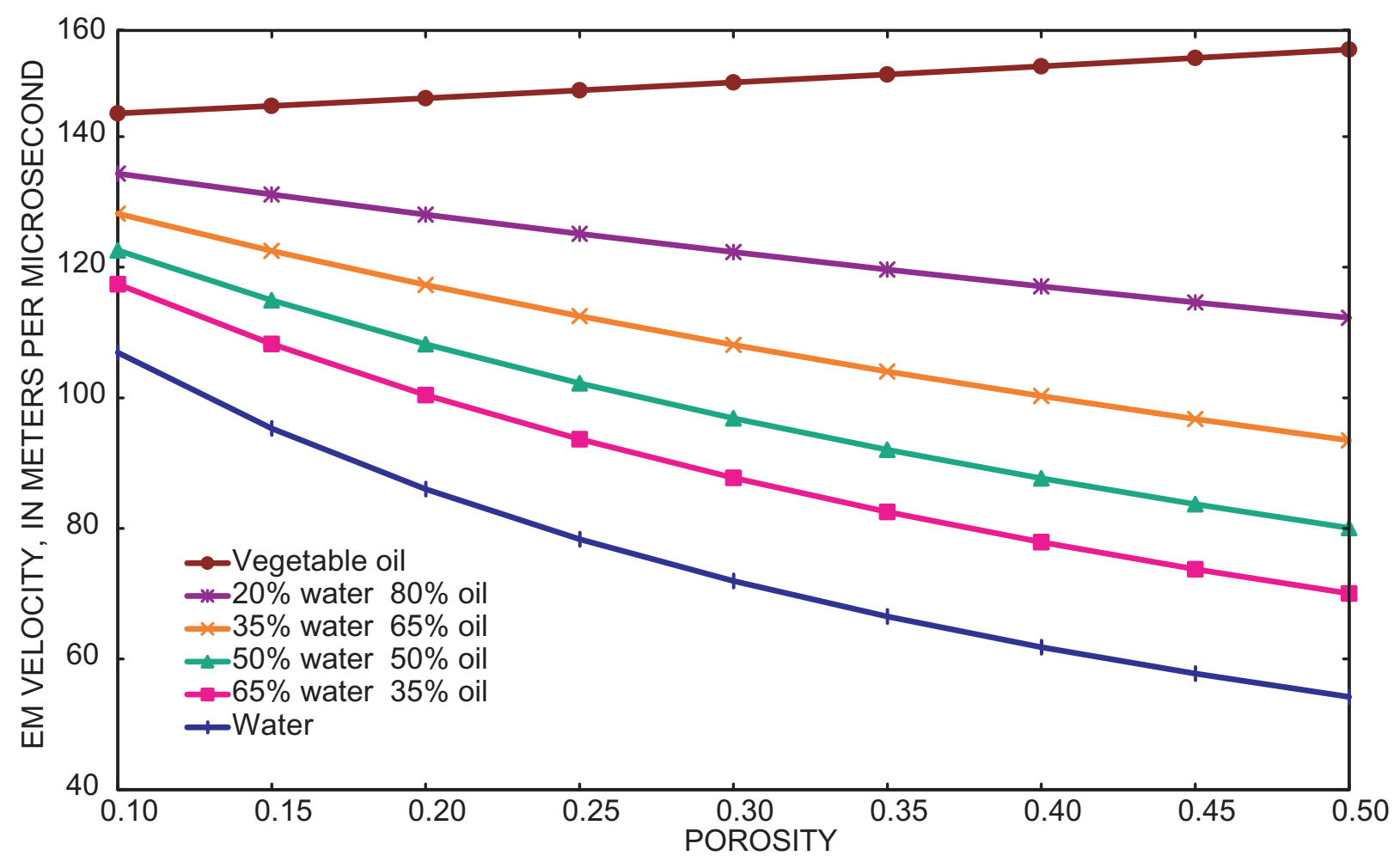

Figure 2. EM wave propagation velocity through quartz sand saturated by vegetable oil emulsions with different water contents plotted against matrix porosity predicted by the complex refractive index method (CRIM). 


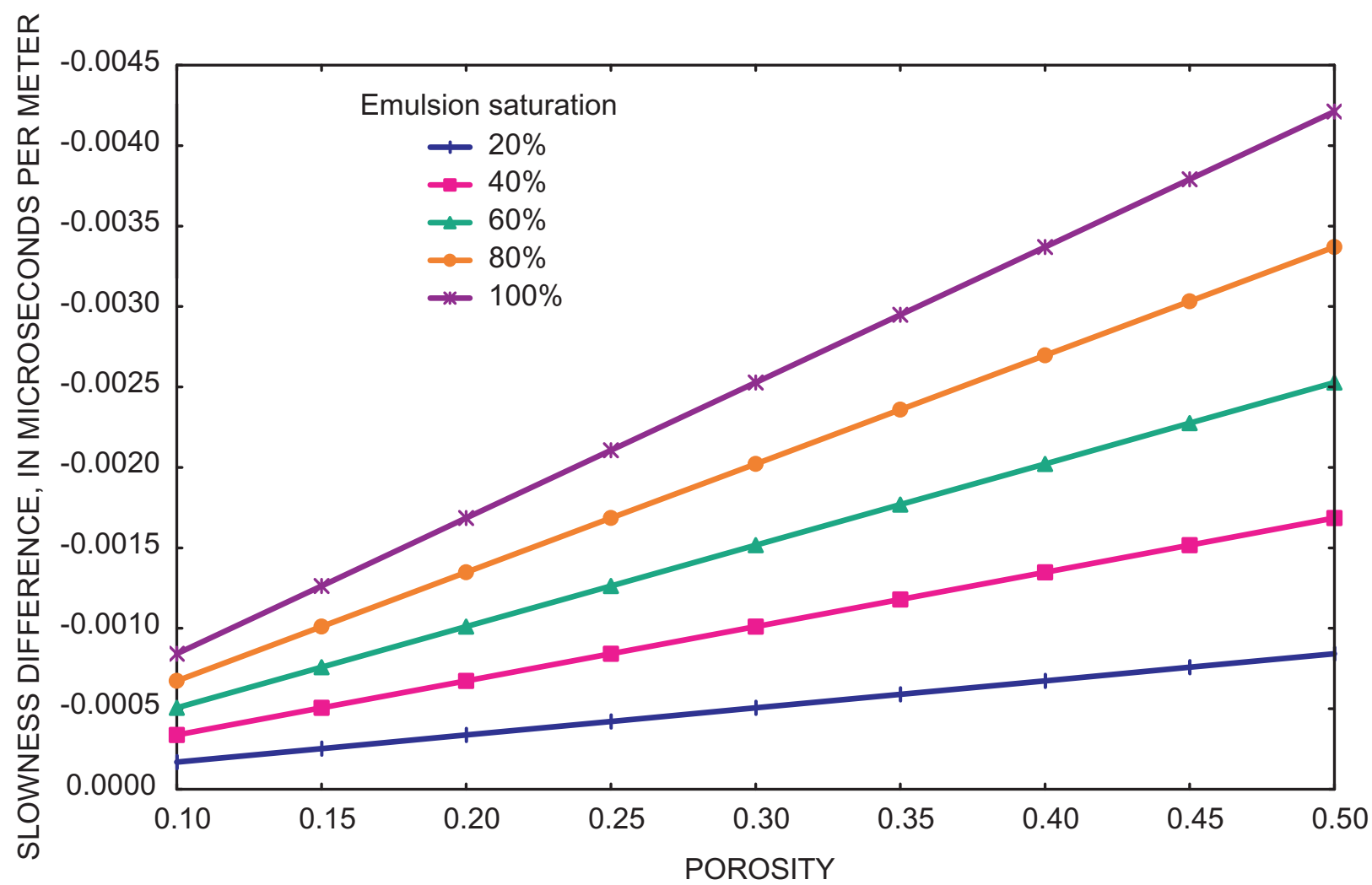

Figure 3. Expected slowness-difference resulting from injecting a vegetable oil emulsion containing $35 \%$ oil and $65 \%$ water into water-saturated quartz sand for different levels of emulsion pore-space saturation plotted against porosity predicted by the complex refractive index method (CRIM). 


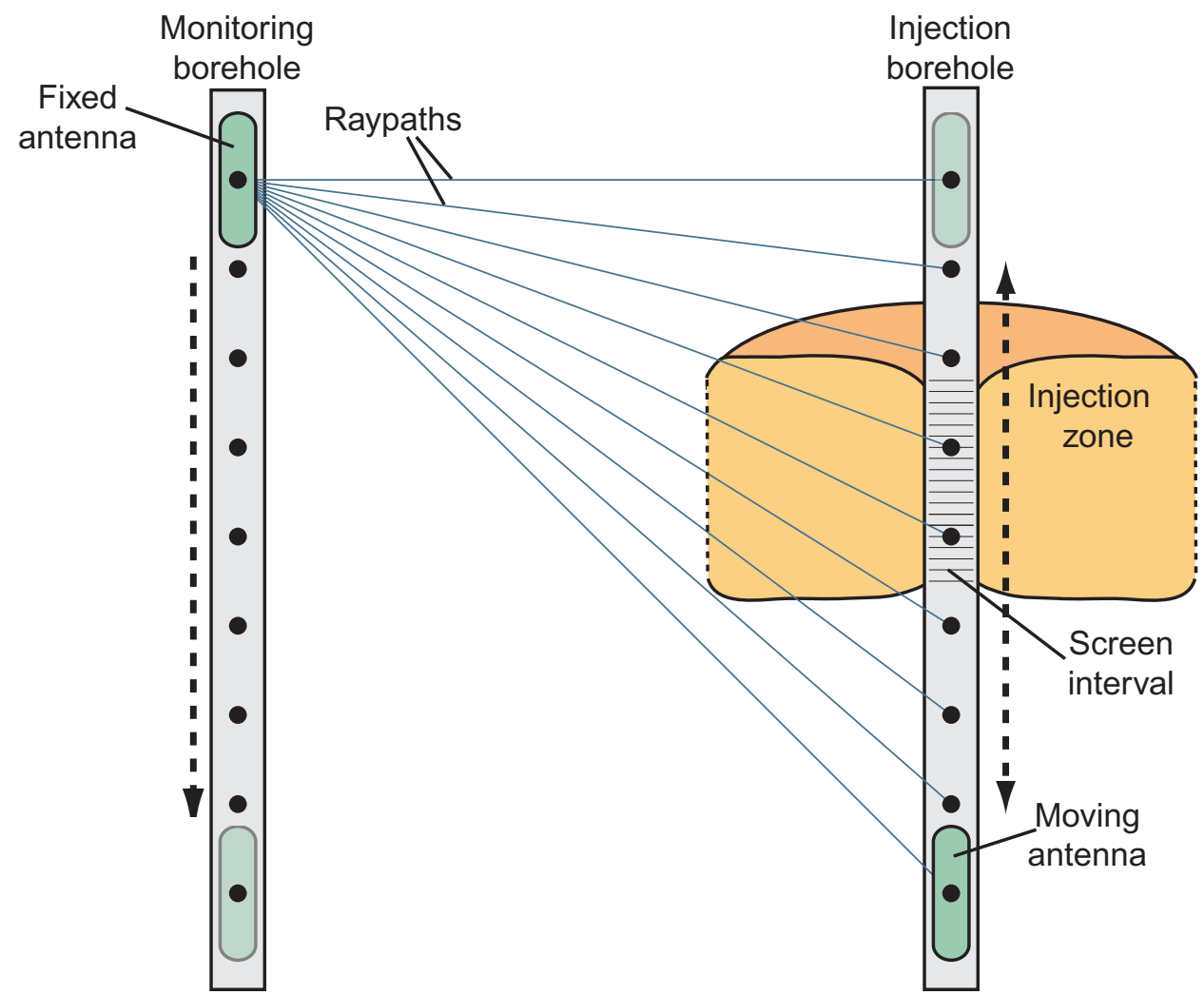

Figure 4. Conceptual diagram of crosswell radar tomography to image vegetable oil emulsion injection.

(a) Model 1

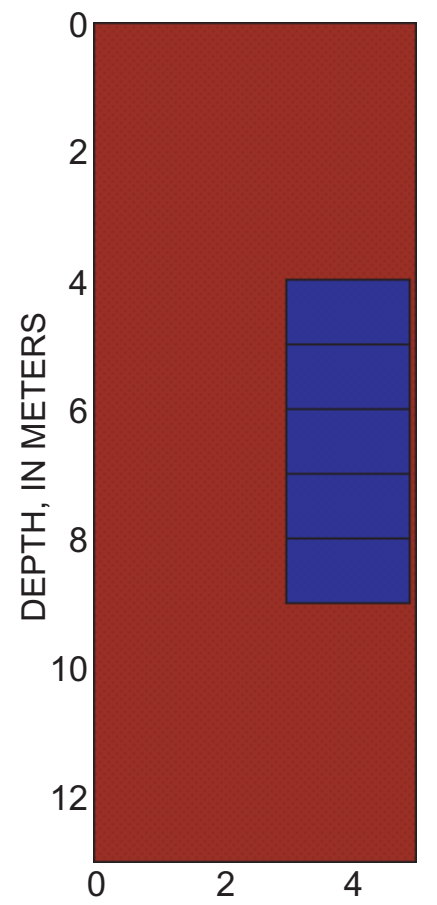

DISTANCE, IN METERS (b) Model 2

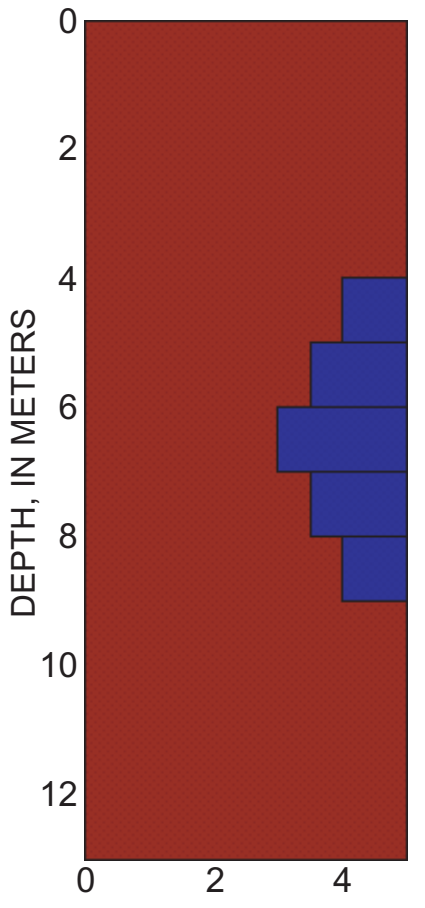

DISTANCE, IN METERS
SLOWNESS DIFFERENCE,

(c) Model 3

IN MICROSECONDS PER METER

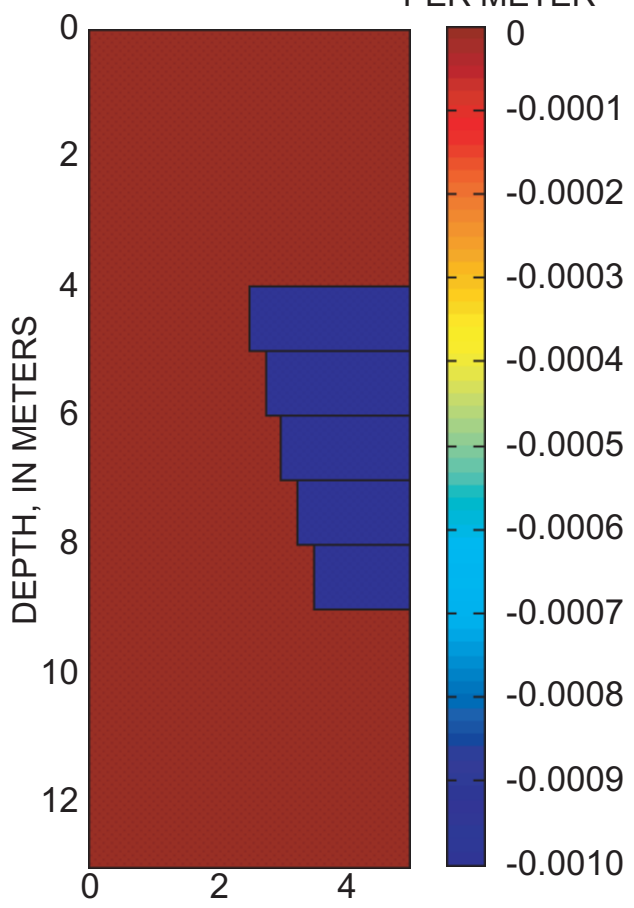

DISTANCE, IN METERS

Figure 5. Diagram showing the geometry and slowness-difference magnitude of anomalies used to forward model crosswell radar travel-time differences for the synthetic modeling experiments. 
and 5c) simulate more complex injectate distribution that could be induced by spatial variability of aquifer hydraulic properties (such as porosity or permeability) in the vicinity of the injection zone. The magnitude of the target anomaly slowness-difference for all models was $-0.001 \mu \mathrm{s} / \mathrm{m}$. An anomaly of this magnitude is consistent with injection of a vegetable-oil emulsion containing $35 \%$ oil and $65 \%$ water into a saturated quartz-sand aquifer with a porosity of $30 \%$ where the emulsion has displaced $50 \%$ of the ground water from the pore space.

Synthetic travel-time difference data were calculated for straight raypaths on a regular $0.5 \mathrm{~m}$ by $0.5 \mathrm{~m}$ transmitter-receiver grid (fig. 6), subject to a maximum transmitter-receiver angular offset of 45 degrees from the horizontal (fig. 7). Measurement error was simulated by adding normally distributed random error to the forward-model travel-time differences with zero mean and a standard deviation of 5\%. Use of the straight-ray approximation is a simplification that is justified for geologic environments where (1) EM-wave velocity is primarily controlled by the real part of the effective dielectric permittivity; (2) background and post-injection velocity contrasts are less than 20\% (Ivansson, 1984); and (3) the ratio of target anomaly size to dominant radar wavelength is consistent with Fresnel-zone considerations (Schuster, 1995; Vasco and others, 1995). More complex geologic environments or injection scenarios could be addressed by incorporating a more computationally intensive ray-bending or full-waveform algorithm into the forward modeling and inversion procedures.

\section{Synthetic Models: Results of Pixel-Based Inversion}

The synthetic travel-time difference data were inverted using the simultaneous iterative reconstruction technique (SIRT) and weighted damped least-squares (WDLS) pixel-based tomographic inversion algorithms. The SIRT algorithm is a finite series-expansion method (Dines and Lytle, 1979; Censor, 1983; McMechan and others, 1987; and Stewart, 1992) based on the algebraic reconstruction technique (ART) (Censor, 1983; Peterson and others, 1985). Both SIRT and ART iteratively update pixel slowness estimates to improve the match to travel-time data, starting from some initial model. For travel-time difference tomography, the ART update to slowness difference in pixel $i, u_{k i}^{A R T}$, for travel-time difference measurement $k$ is:

$$
u_{k i}^{A R T}=\frac{\Delta t_{k}^{o b s}-\Delta t_{k}^{\text {pred }}}{\sum_{i=1}^{\text {npixels }} G_{k i}^{2}} G_{k i},
$$

where

$\Delta t_{k}^{o b s}$ is the observed difference travel time along raypath $k$;

$\Delta t_{k}^{\text {pred }}$ is the calculated difference travel time along raypath $k$, for the current estimate of difference slowness; and

$G_{k i}$ is the distance of raypath $k$ in pixel $i$.

In the SIRT algorithm, the ART update for every travel time is calculated before updating the current estimate of difference slowness. The SIRT update is calculated as the mean of the ART updates:

$$
u_{i}^{S I R T}=\lambda \frac{1}{n \text { data }} \sum_{k=1}^{\text {ndata }} u_{k i}^{A R T}
$$




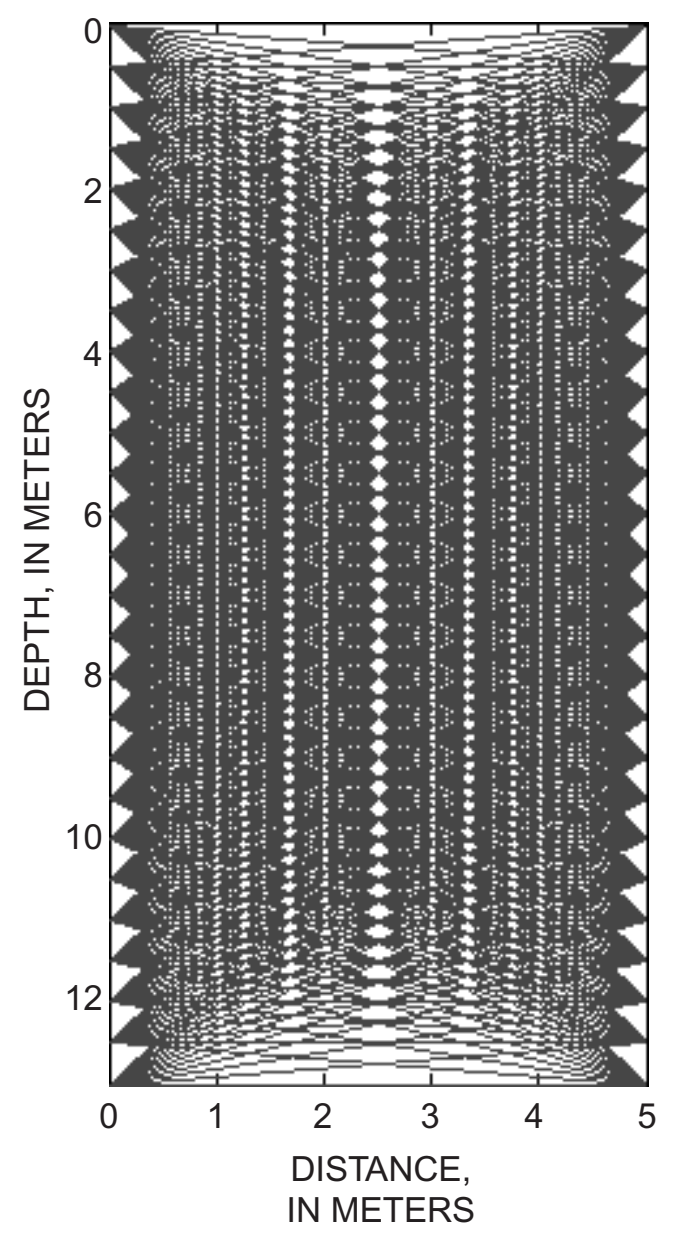

Figure 6. Simulated crosswell transmitter-receiver geometry used to generate travel-times for the synthetic experiments. Raypaths simulate location of the transmitter and receiver every 0.5 meters over the model domain.

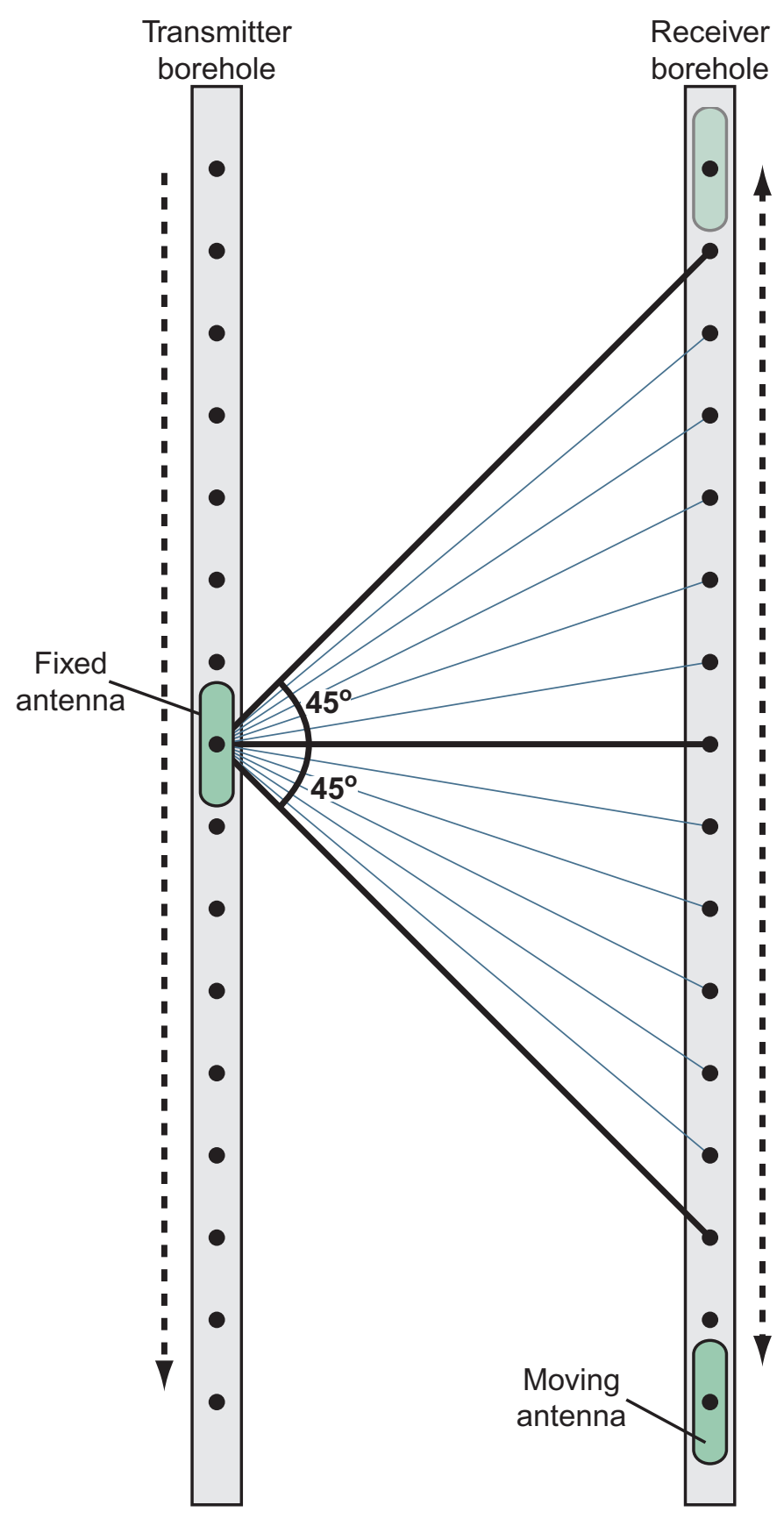

Figure 7. Conceptual diagram of typical raypath and 45 degree limit in transmitter to receiver angular coverage. 
where $\lambda$ is a relaxation parameter (greater than zero and less than one), used to improve stability and aid convergence, and ndata is the number of travel-time data. Thus, in SIRT, the slowness field is updated once for each cycle through the travel-time data. The updating process is repeated until (a) the mean squared error between measured and predicted difference travel times converges to less than specified tolerance, (b) changes to pixel slowness estimates stabilize at less than a specified tolerance, or (c) a maximum number of iterations is reached.

The WDLS inversion implemented in this study follows the approach presented in Lane and others (2000), Day-Lewis and others (2002), and Day-Lewis and others (in review). The WDLS inversion minimizes the combination of (a) the sum of weighted, squared-data residuals, and (b) a measure of solution complexity based on an a priori covariance model:

$$
F=\left(\Delta \mathbf{t}^{o b s}-\mathbf{G} \Delta \mathbf{s}\right)^{T} \mathbf{W}^{-1}\left(\Delta \mathbf{t}^{o b s}-\mathbf{G} \Delta \mathbf{s}\right)+(\Delta \mathbf{s}-\mathbf{X} \boldsymbol{\beta})^{T} \mathbf{Q}^{-1}(\Delta \mathbf{s}-\mathbf{X} \boldsymbol{\beta}),
$$

where

$\Delta \mathbf{t}^{o b s}$ is the data vector containing observed, difference travel times;

$\mathbf{G} \quad$ is the data kernel, containing elements $G_{i j}$ equal to the length of ray $i$ in pixel $j$;

$\Delta \mathbf{s} \quad$ is the vector of difference slowness, to be determined by inversion;

W is a diagonal matrix with elements equal to the error variances of the difference travel times;

$\mathbf{Q} \quad$ is the prior covariance matrix of $\Delta \mathbf{s}$;

$\mathbf{X}$ is a matrix defining the form of the mean (such as a spatially uniform mean, zonal mean, or mean with a linear trend); and

$\beta \quad$ are the mean values determined by the inversion.

The minimization of (5) is found by solving a linear system of equations (6) for the vector $\Delta \mathbf{s}$.

where

$$
\left(\mathbf{G}^{T} \mathbf{W}^{-1} \mathbf{G}+\mathbf{M}\right) \boldsymbol{\Delta} \mathbf{s}=\mathbf{G}^{T} \mathbf{W}^{-1} \Delta \mathbf{t},
$$

$$
\mathbf{M}=\mathbf{Q}^{-1}-\mathbf{Q}^{-1} \mathbf{X}\left(\mathbf{X}^{T} \mathbf{Q}^{-1} \mathbf{X}\right)^{-1} \mathbf{X}^{T} \mathbf{Q}^{-1}
$$

Although the form of the mean is assumed a priori, the mean value(s) are determined by the inversion procedure. In this study, we assume a constant mean, and a spherical covariance with an isotropic spatial range.

The SIRT inversion results for the three synthetic models are shown in figures 8 to 10 (panel b). The travel-time difference data were inverted using a pixel size of $0.5 \mathrm{~m} \times 0.5 \mathrm{~m}$. The relaxation parameter, $\lambda$, was set to 0.5 . Inversion was halted after 10 iterations. The SIRT inversion successfully identifies the top, bottom, and general location of the target anomalies in the image plane; however, the shapes of the anomalies are poorly resolved and the horizontal extent of the anomalies is overestimated. Spurious streaking of the anomaly parallel to highangle rays is present in all of the tomograms and fictitious slowness increases can be observed above and below the target zones. In addition, the maximum magnitude of the slowness difference anomaly is underestimated by about $40 \%$. 

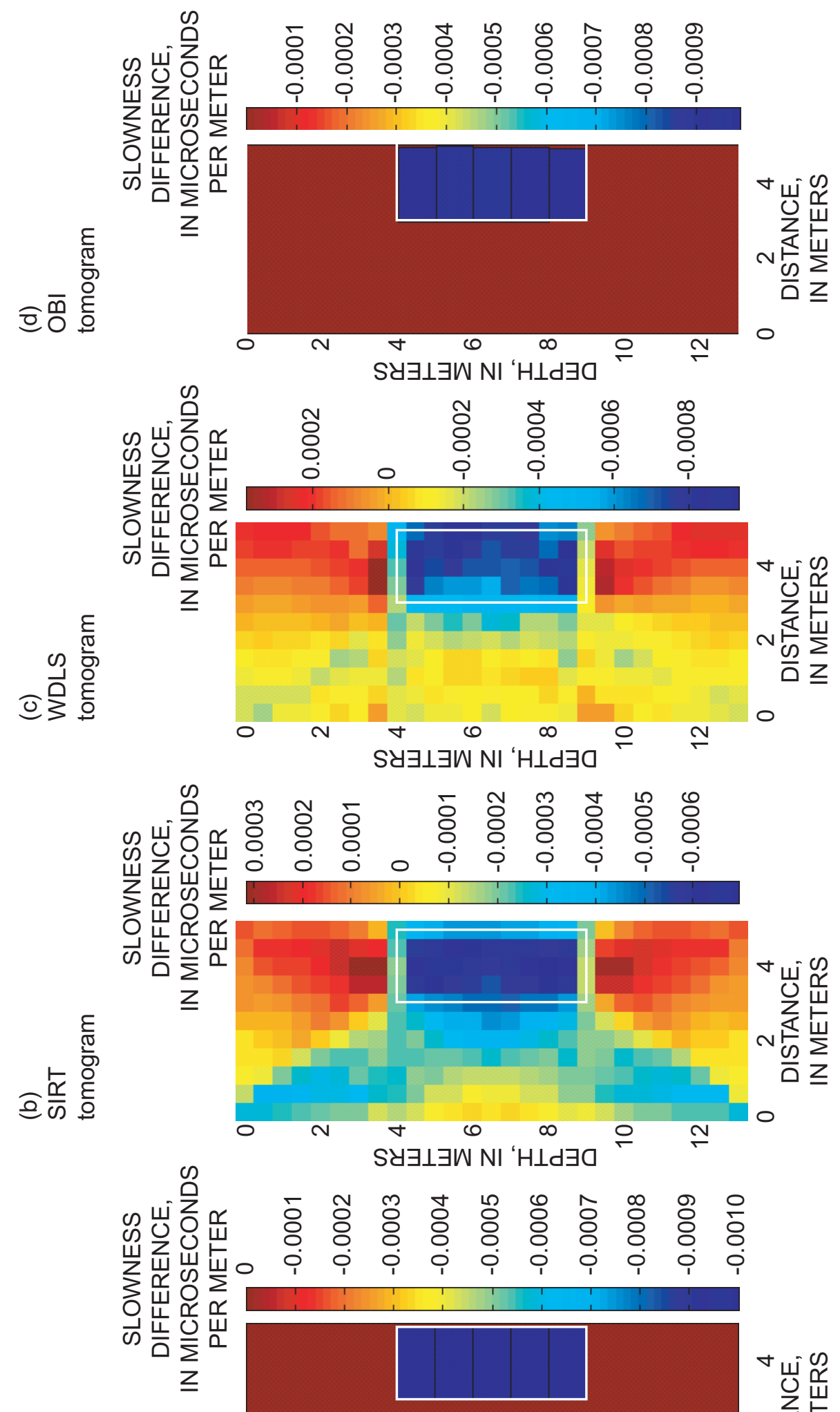

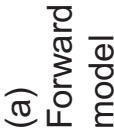

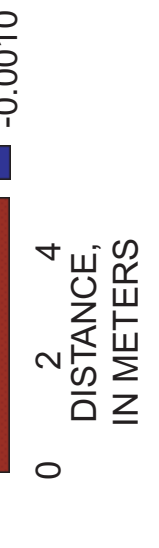

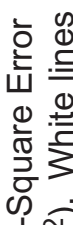

文

$\sum^{\infty} \infty$

을

홍

品

क

의

힝 웅

몬

응

(이 으

क)

응

$\varepsilon_{\infty}$

음으

핮

के छ

흐 II

常

Ð

충항

ธัँ

है

03

응중

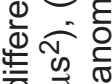

is o

क⿺辶万

文

응 월

の ले

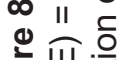

믕 तٓ 

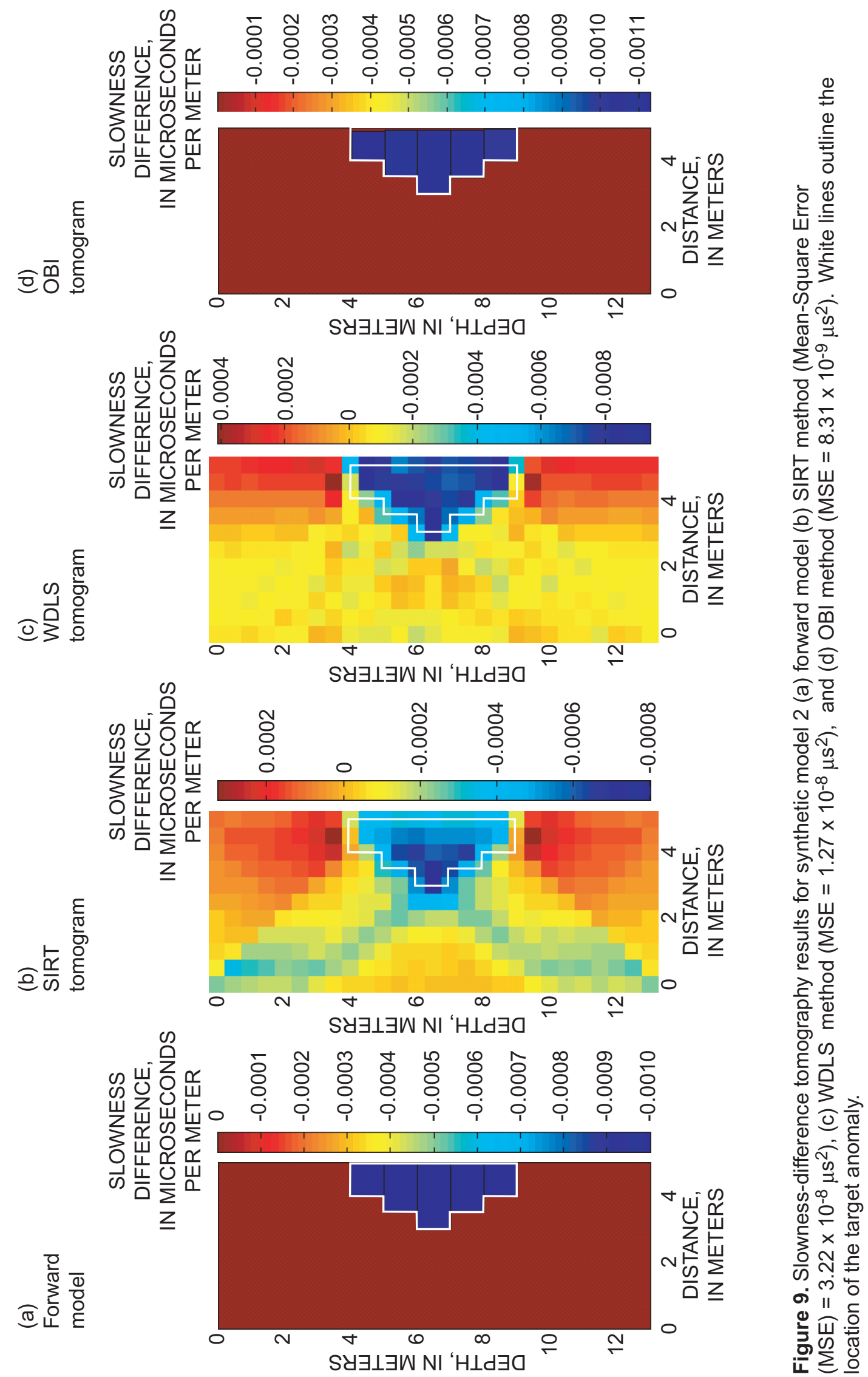

지난
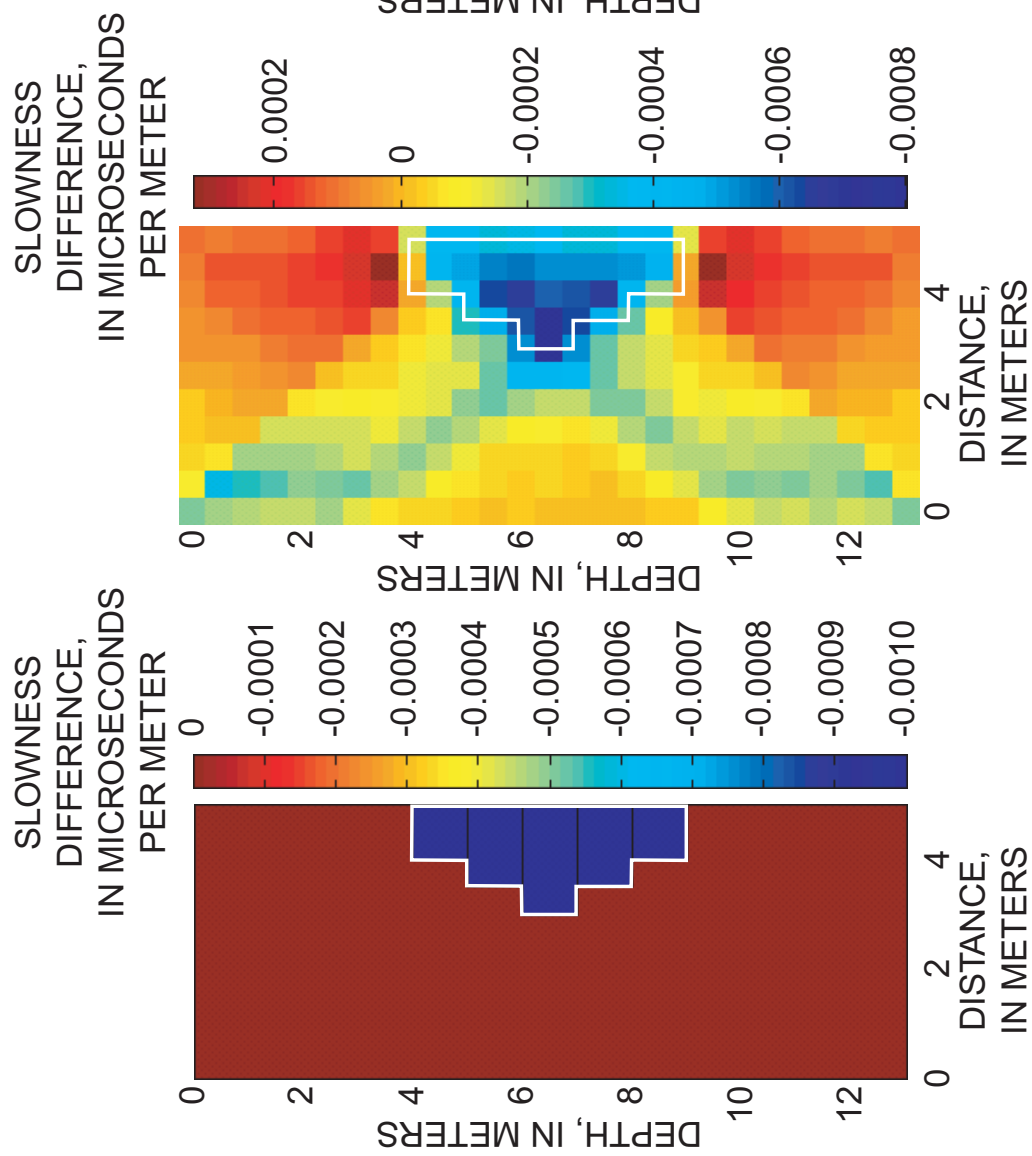

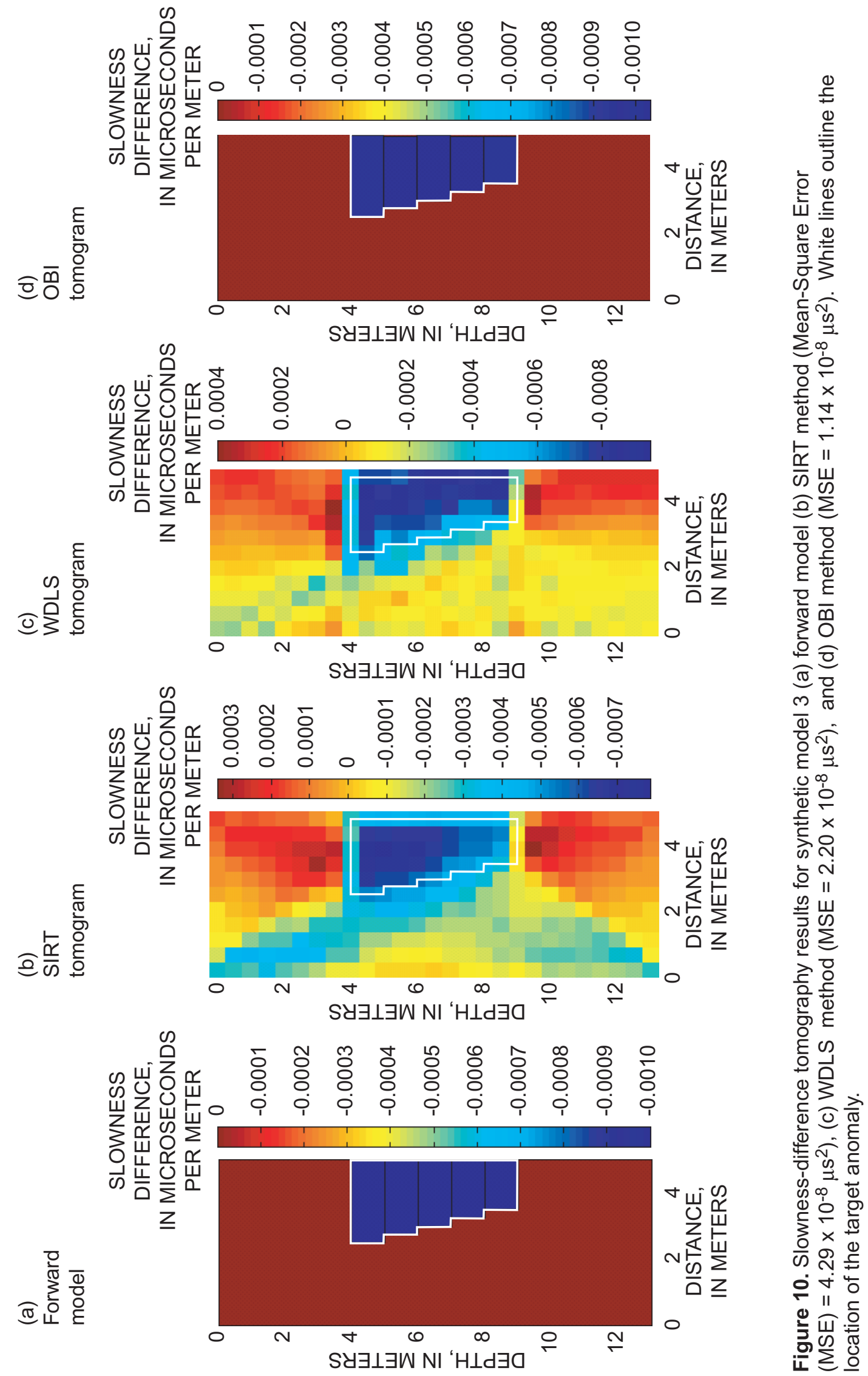
The WDLS inversion results for the three synthetic models are shown in figures 8 to 10 (panel c). The travel-time difference data were inverted using a pixel size of $0.5 \mathrm{~m} \times 0.5 \mathrm{~m}$. The model variance was set to $0.01 \mu \mathrm{s}^{2} / \mathrm{m}^{2}$ with an isotropic range of $5.0 \mathrm{~m}$.

The WLDS inversion results are superior to the SIRT results. Using WDLS, the top, bottom, and general location of the target anomalies in the image plane are properly identified, and the shapes of the anomalies are better resolved. The horizontal extent of the anomalies is overestimated, but not to the degree observed in the SIRT inversions. Some spurious streaking of the anomaly parallel to high-angle rays is present in the tomograms for models 1 and 3 . The fictitious slowness increases observed in the SIRT inversions are also observed in the WDLS inversions. Using WDLS, the magnitude of the target zone anomalies are better resolved than with SIRT, but are still underestimated by about $20 \%$.

\section{Synthetic Models: Results of Object-Based Inversion}

The OBI method presented in this study employs a small number of "objects" rather than a large number of pixels to produce an overdetermined inverse problem that eliminates the need to impose regularization criteria such as smoothness or damping or assumption of an a priori covariance model. In this study, the nature and geometry of the objects used for OBI are based on (a) a simplified conceptual model of the physics of oil-water displacement, and (b) the geologic structure of the aquifer, i.e., horizontally stratified unconsolidated sediments. We use an object-based parameterization in which the injectate-affected region (the "object") is discretized as a stack of rectangles of variable horizontal extent and difference slowness. The inversion parameters include (a) the top elevation, $Z_{t o}$, of the affected region; (b) the bottom elevation, $\mathrm{Z}_{b o t}$, of the affected region; (c) the left-most extent, $R_{i}^{L}$, of each rectangle in the affected region; (d) the right-most extent, $R_{i}^{R}$, of each rectangle in the affected region; (e) the slowness change, $\Delta \mathrm{s}_{i}$, in each rectangle; and (f) the slowness change, $\Delta \mathrm{s}_{\text {back }}$, outside the affected region, (which should be close to zero for this problem) (fig.11). Thus, if the region affected by injection is discretized into nrows, the number of inversion parameters, npar, is:

$$
\text { npar }=3 \text { nrows }+3 \text {. }
$$

The non-linear inversion procedure we use seeks to identify the set of object parameters that minimize the sum of weighted squared residuals between the observed and predicted travel times:

where

$$
F=\left(\Delta \mathbf{t}^{o b s}-\Delta \mathbf{t}^{\text {pred }}(\mathbf{p})\right)^{T} \mathbf{W}^{-1}\left(\Delta \mathbf{t}^{\text {obs }}-\boldsymbol{\Delta} \mathbf{t}^{\text {pred }}(\mathbf{p})\right),
$$

$\mathbf{p}$ is the vector of object parameters, including $\Delta \mathrm{s}_{i=1, \ldots n}, \mathrm{R}_{i=1, \ldots n}, \mathrm{Z}_{t o p}$, and $\mathrm{Z}_{\text {bot }}$, and, $\Delta \mathbf{t}^{\text {pred }}$ is the vector of predicted, difference travel times for parameters $\mathbf{p}$.

The minimization of (9) is implemented using a subspace trust-region method based on the interior-reflective Newton method (Coleman and Li, 1994, 1996) within the Matlab Optimization Toolbox ${ }^{1}$. Although the formulation of (9) does not include prior information, the OBI

\footnotetext{
${ }^{1}$ The use of firm, trade, and brand names in this report is for identification purposes only and does not constitute endorsement by the U.S. Government.
} 
Tomographic Image Plane

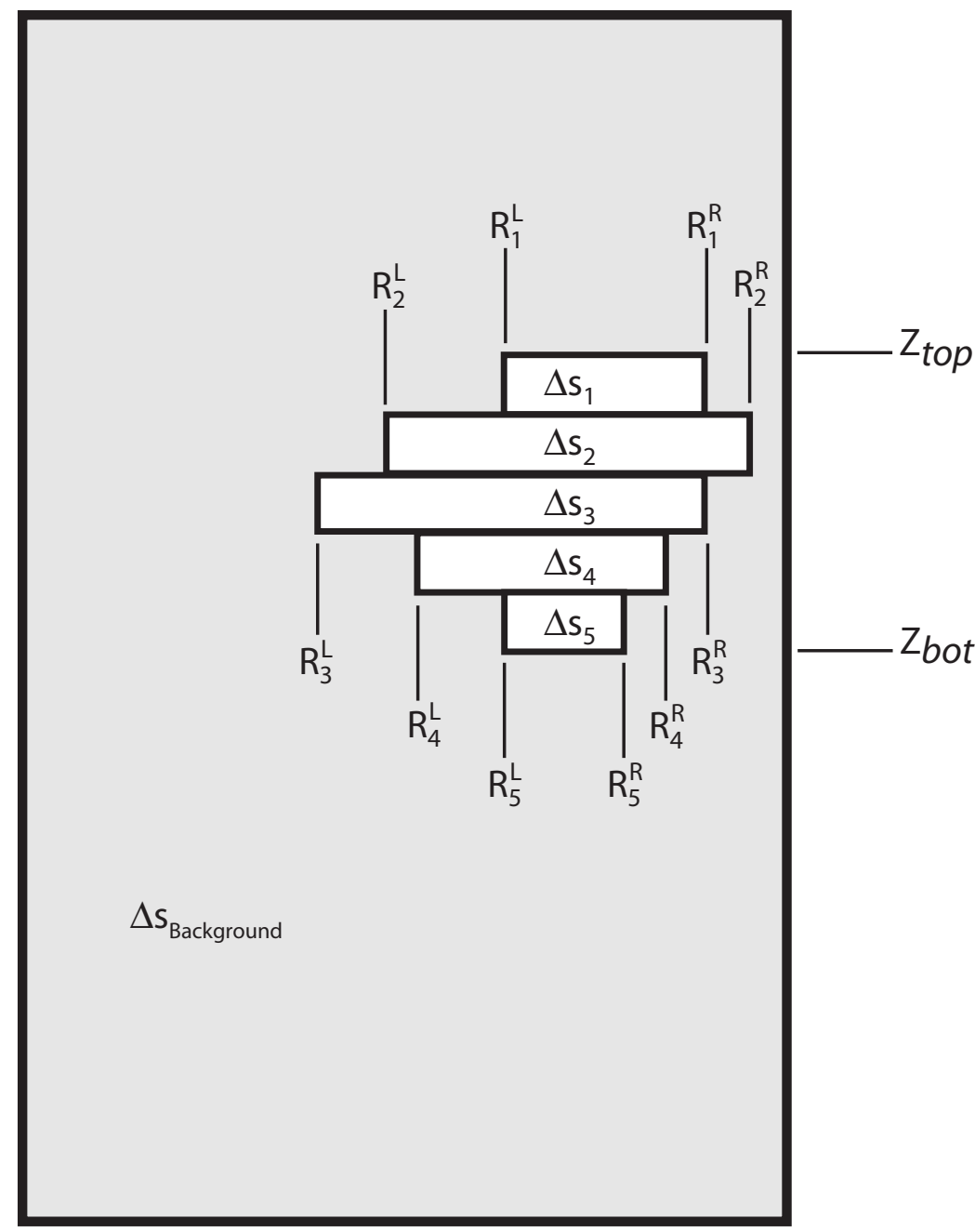

Figure 11. Conceptual diagram of the object-based parameterization of $\Delta \mathrm{s}$ in the tomographic image plane. The region affected by oil-tracer injection is discretized as an object comprised of a small number of rectangles. The shape and extent of the affected region are determined by the inversion. 
methodology presented here could be adapted to include, if necessary, regularization criteria such that variations in $\Delta \mathrm{s}$ or $R$ between adjacent rectangles should be small.

The OBI results for the three synthetic models are shown in figures 8 to 10 (panel d). The travel-time difference data were inverted using a 5-layer model. Starting values for $Z_{\text {top }}$ and $\mathrm{Z}_{\mathrm{bot}}$ (the top and bottom of the region affected by injectate) were selected based on WDLS inversion results (figs. 8c-10c). The starting model for each OBI inversion was a rectangular zone $2 \mathrm{~m}$ wide starting at a horizontal distance of $2 \mathrm{~m}$ from the injection well (fig. 12). The starting model slowness difference was set to $-0.01 \mu \mathrm{s} / \mathrm{m}$.

The tomograms generated using OBI closely match the synthetic models in shape, horizontal extent, and anomaly magnitude. Errors in the estimation of the vertical and horizontal extent of the anomalies are less than $2 \%$. For models 1 and 3 , errors in the estimation of the magnitude of the anomaly are less than $2 \%$; for model 2 , the magnitude estimate error is less than $6 \%$.

The OBI method requires definition of an appropriate starting model. If a poor starting model is assumed, OBI estimates of anomaly location and magnitude will be inaccurate. Figure 13 illustrates the effect of starting model selection on inversion results for synthetic model 2 . Raising the top and bottom of the starting model anomaly 0.25 and $0.5 \mathrm{~m}$ above the true boundaries of the anomaly produces increasingly erroneous estimates of the anomaly boundary and magnitude. Our experience with OBI suggests robust approximation of anomaly location is more important than anomaly magnitude. If assumed starting model boundaries are accurate, initial order-of-magnitude over- or under-estimates of anomaly magnitude produced similar final estimates. Results of pixel-based algorithms can be used to delineate the starting model anomaly boundary.

Inversion of the travel-time difference data using the OBI algorithm takes significantly longer to run than the SIRT or WDLS algorithms, owing to repeated ray tracing and the nonlinear sensitivity of simulated travel times to object parameters. To achieve mean-square error (MSE) values similar to those achieved by SIRT of WDLS inversion, 30 to 90 iterations of the OBI algorithm were required. Run-times ranged from 5 to 15 minutes using a Pentium III processor operating at $700 \mathrm{Megahertz}(\mathrm{MHz})$ compared to a few seconds using SIRT or WDLS.

The results of the synthetic modeling illustrate some of the limitations of pixel-based tomographic inversion methods including poor resolution of the target anomaly shape, overestimation of target horizontal extent, spurious streaking of the anomaly parallel to high angle rays, fictitious slowness increases above and below the target anomalies, and a general underestimation of target anomaly magnitude. Although the pixel-based algorithms, particularly WDLS, can be used to identify the general location, vertical extent, and shape of the differenceslowness anomalies induced by vegetable-oil emulsions, underestimation of the magnitude of the anomaly limits precludes the use of petrophysical models to make useful estimates of vegetableoil emulsion saturation in the injection zone.

Using OBI, the vertical and horizontal extent and shape of the target anomalies were accurately reproduced and errors in the estimates of anomaly magnitude were consistent with the data error. OBI requires an appropriate starting model, such as one based on the results of pixelbased inversion. The synthetic modeling results suggest that the OBI approach can produce robust estimates of anomaly shape and magnitude. In geologic environments where vegetable-oil emulsion injection is controlled by horizontally stratified sediments, petrophysical analysis of velocity contrasts to estimate vegetable-oil emulsion saturation could be undertaken with greater confidence using OBI. The OBI methodology presented here could be extended for use in other 


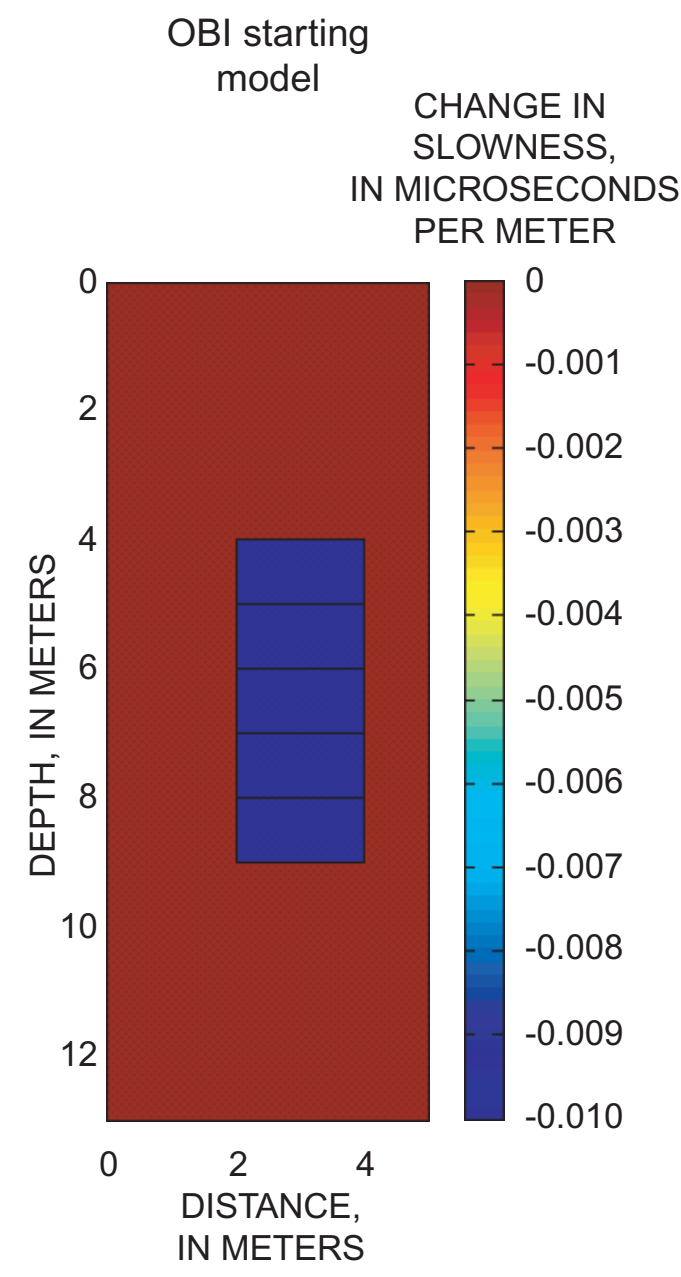

Figure 12. Diagram showing the geometry and slowness-difference magnitude of the starting model used to invert the synthetic model data using the Object-Based Inversion (OBI) method. 
SLOWNESS DIFFERENCE,

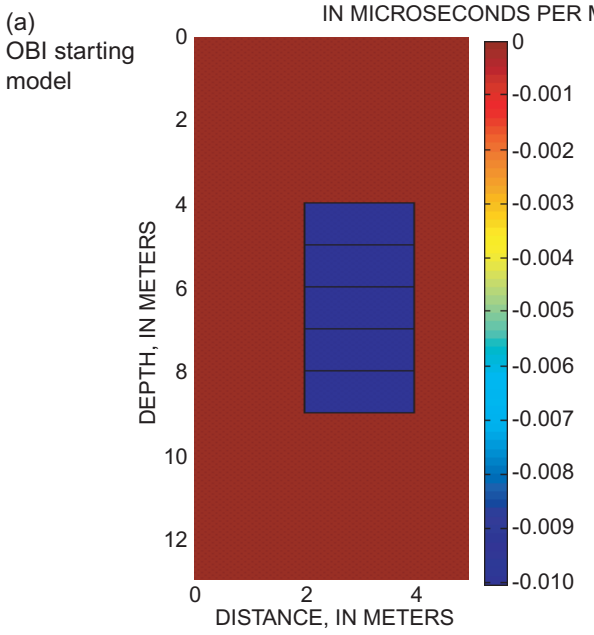

SLOWNESS DIFFERENCE,
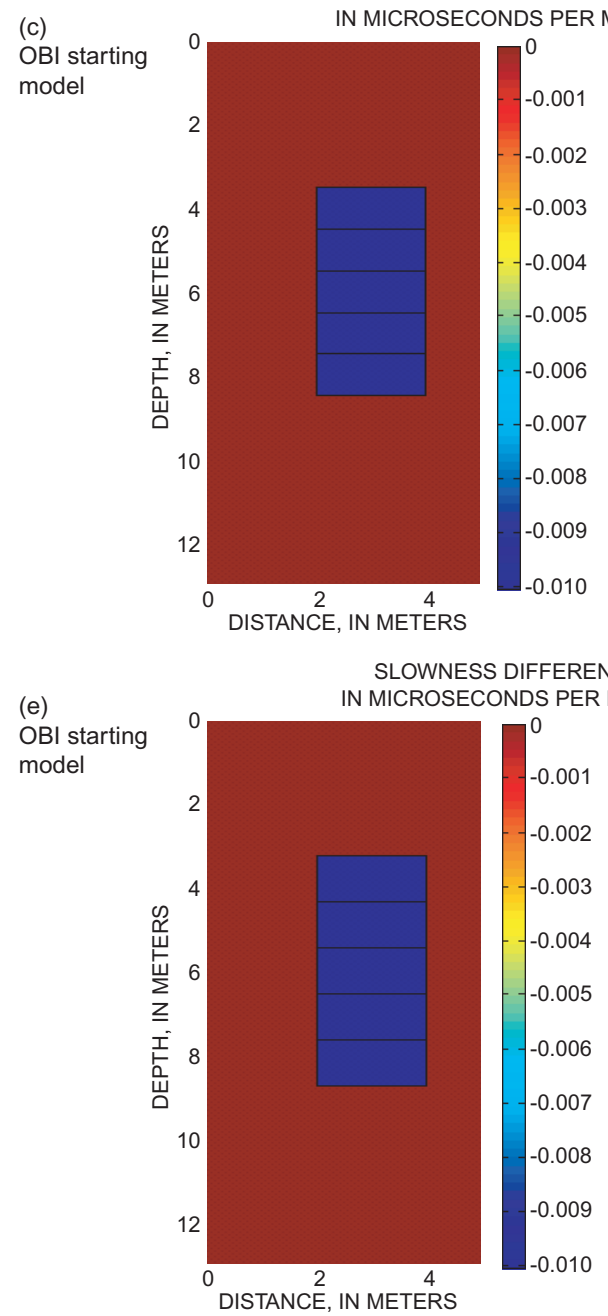

(b)

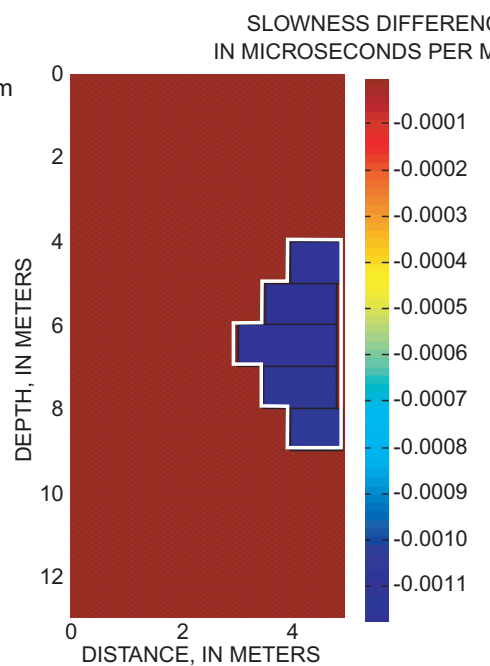

SLOWNESS DIFFERENCE,

(d)

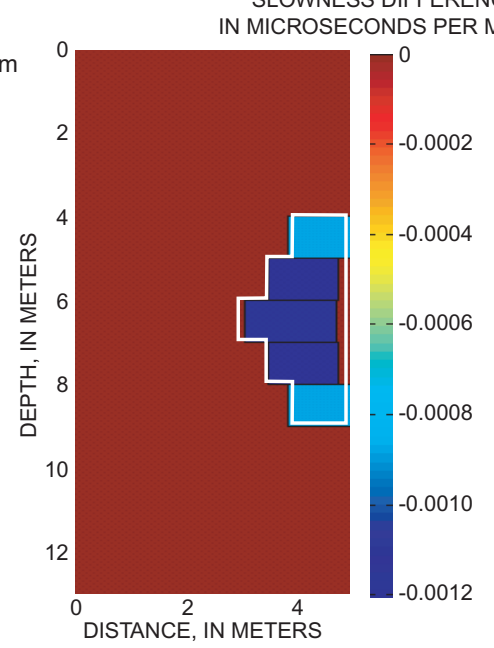

SLOWNESS DIFFERENCE,

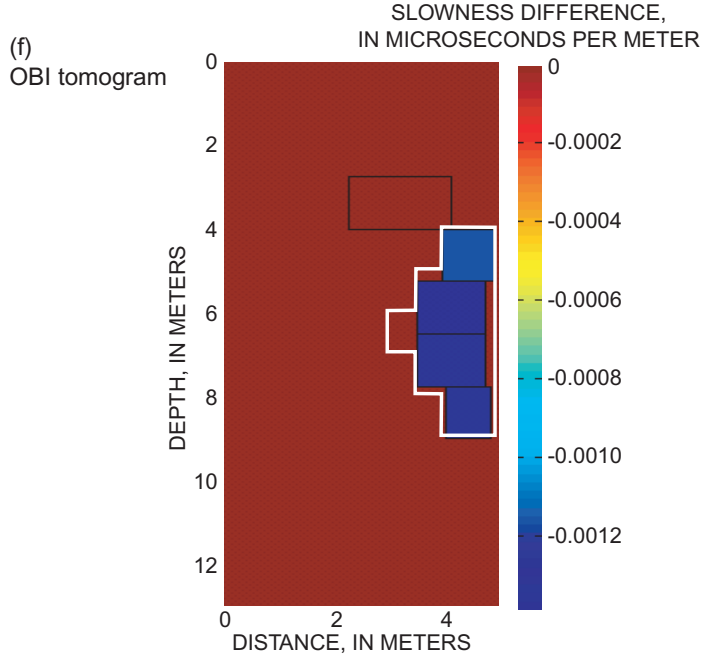

Figure 13. Slowness-difference tomography results for synthetic model 2 showing the effects of starting model parameterization on OBI tomograms (a) starting model centered on anomaly top and bottom, (b) OBI tomogram (Mean-Square Error $(\mathrm{MSE})=6.82 \times 10^{-9} \mu \mathrm{s}^{2}$ ), (c) starting model 0.25 meters above anomaly top and bottom, (d) OBI tomogram (MSE $\left.=5.70 \times 10^{-9} \mu \mathrm{s}^{2}\right)$, (e) starting model 0.50 meters above anomaly top and bottom, (f) OBI tomogram (MSE $=2.80 \times 10^{-8} \mu \mathrm{s}^{2}$ ). 
environments or for different injection procedures by defining alternative "objects" based on appropriate, simple geometries. An important advantage of OBI is the simplicity of the tomograms produced, which can be readily interpreted by hydrologists and engineers.

\section{Field Experiment}

The pixel-based and OBI inversion methods were applied to crosswell radar travel-time field data acquired in support of a U.S. Navy field-scale vegetable-oil biostimulation pilot project underway at Anoka County Riverfront Park (ACP), a site located down-gradient of the Naval Industrial Reserve Ordnance Plant (NIROP), Fridley, Minnesota (fig. 14). As a result of industrial activities, ground water in the vicinity of NIROP is contaminated with VOCs including trichloroethane (TCA) and dichloroethane (DCE) (CH2M Hill, 2002). In cooperation with Federal and State regulators, the Southern Division Naval Facilities Engineering Command implemented a field-scale pilot project to determine if biostimulation using vegetable-oil injection could provide a viable alternative to an existing pump-and-treat remediation and hydraulic-containment system (CH2M Hill, 2002). Crosswell radar tomography was one of several borehole- and surface-geophysical methods used by the U.S. Geological Survey at the ACP site to monitor injection of the vegetable oil.

For the field example presented here, we analyze crosswell radar data collected between injection well INJ-3 and monitoring well, MW-07, located about $4.5 \mathrm{~m}$ down-gradient (fig. 15). Wells INJ-3 and MW-07 penetrate unconsolidated coarse- to fine-grained sand and silts. Both wells are about $21 \mathrm{~m}$ deep, completed using PVC casing with an inner diameter of 3 in, and are screened from 12.2 to $15.2 \mathrm{~m}$ below ground surface (bgs). About 13,700 liters $\left(13.7 \mathrm{~m}^{3}\right)$ of a vegetable-oil emulsion containing 35\% soybean oil and lecithin (an emulsifier) and 65\% water were injected through the 3-m section of the well screen in INJ-3. At the time of injection, the water table in the vicinity of the injection zone was about $8 \mathrm{~m}$ bgs; therefore, about $4 \mathrm{~m}$ of saturated sediments separated the top of the well screen from the unsaturated zone.

Radar data were acquired before and after injection with a Malå GeoScience RAMAC borehole-radar system using broad-band electric-dipole antennas with a center frequency in air of about $100 \mathrm{MHz}$. The transmitter-receiver positions used for the pre- and post-injection tomography surveys are shown in figure 16.

\section{Field Experiment: Results of Pixel-Based Inversion}

Travel-time difference data were inverted using the SIRT and WDLS algorithms subject to the same inversion parameters applied in the synthetic examples. In general, field-data inversion results using the pixel-based inversion methods are consistent with the results obtained from the synthetic models. The SIRT tomogram (fig. 17a) contains a negative slownessdifference anomaly that extends horizontally across the entire image plane and vertically from about 12 to $18 \mathrm{~m} \mathrm{bgs.} \mathrm{The} \mathrm{tomogram} \mathrm{contains} \mathrm{streaks} \mathrm{that} \mathrm{parallel} \mathrm{the} \mathrm{high-angle} \mathrm{rays} \mathrm{and}$ slowness-difference increases are observed above and below the injection zone (12.2 to $15.2 \mathrm{~m} \mathrm{bgs})$. The maximum magnitude of the injection zone anomaly is about $-0.002 \mu \mathrm{s} / \mathrm{m}$.

The WDLS tomogram (fig. 17b) contains a negative slowness-difference anomaly with a vertical and horizontal distribution similar to the SIRT tomogram, but the horizontal extent of the highest magnitude zone is better defined, terminating about $2 \mathrm{~m}$ from MW-07. Similar to the 


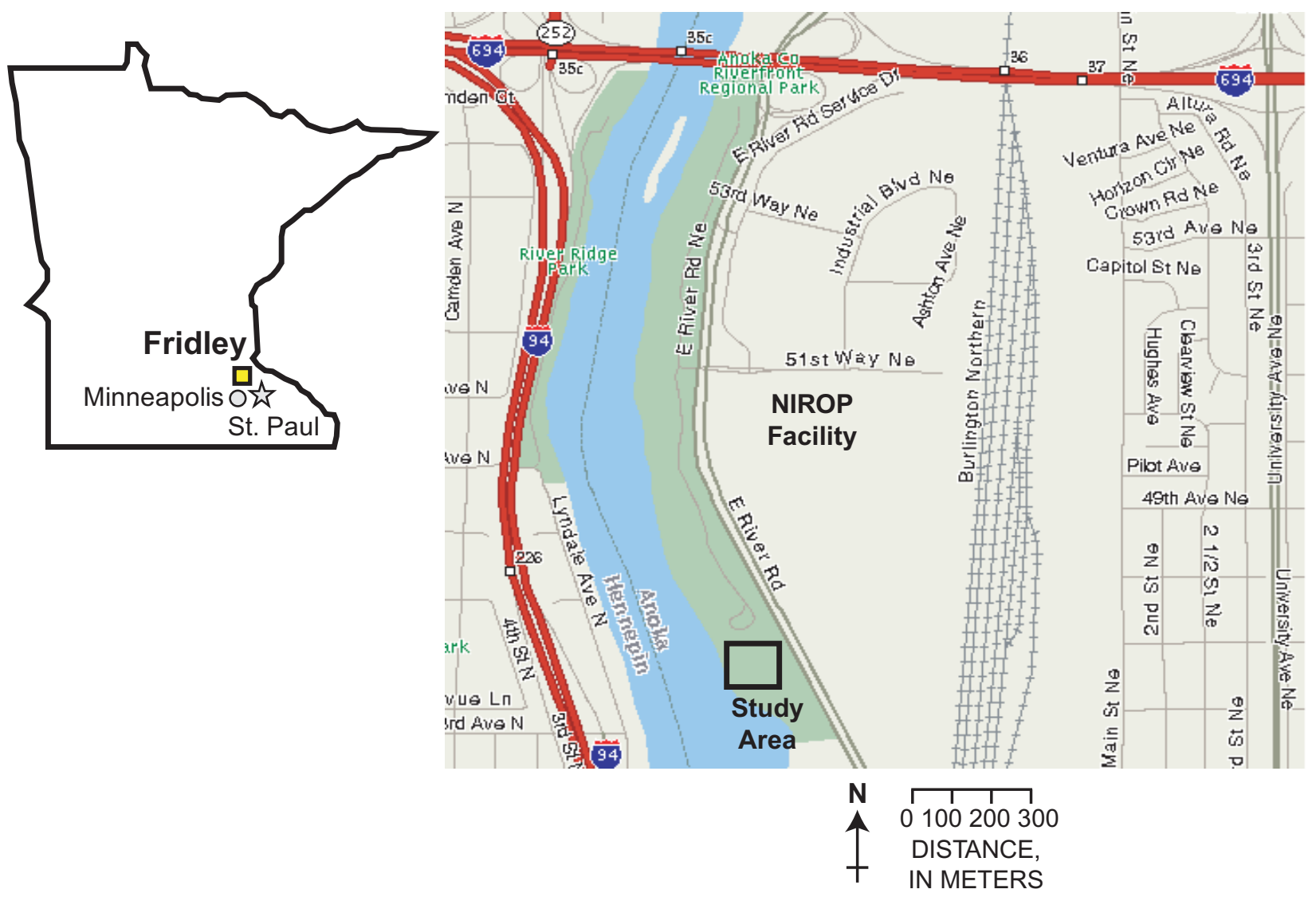

Figure 14. Location of the study area, Anoka County Riverfront Park, Fridley, Minnesota.

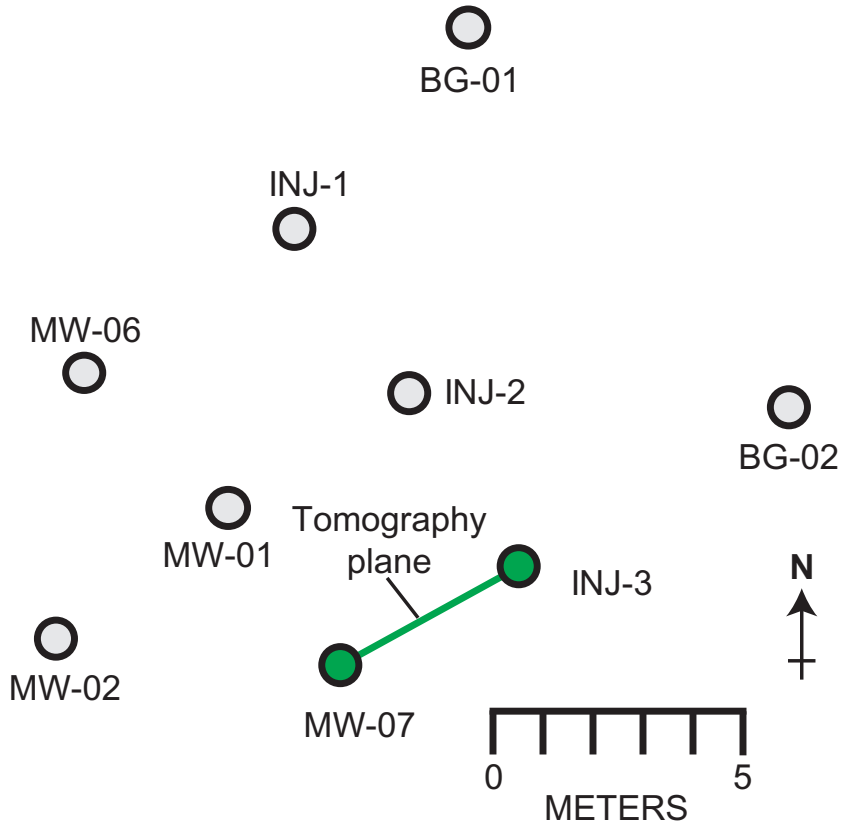

Figure 15. Map of the study area well field; wells MW-07 and INJ-3 (highlighted) were used for crosswell radar tomography surveys.

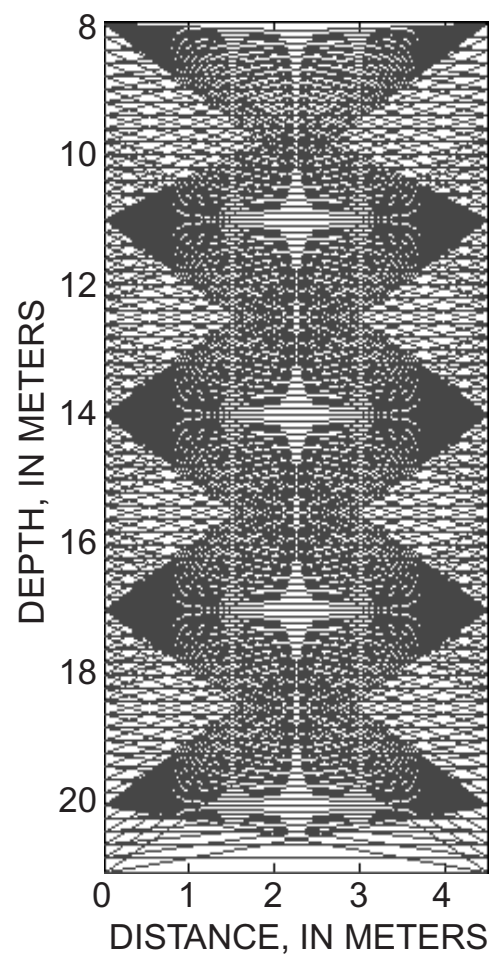

Figure 16. Crosswell radar tomography transmitter-receiver geometry used for the field study. 


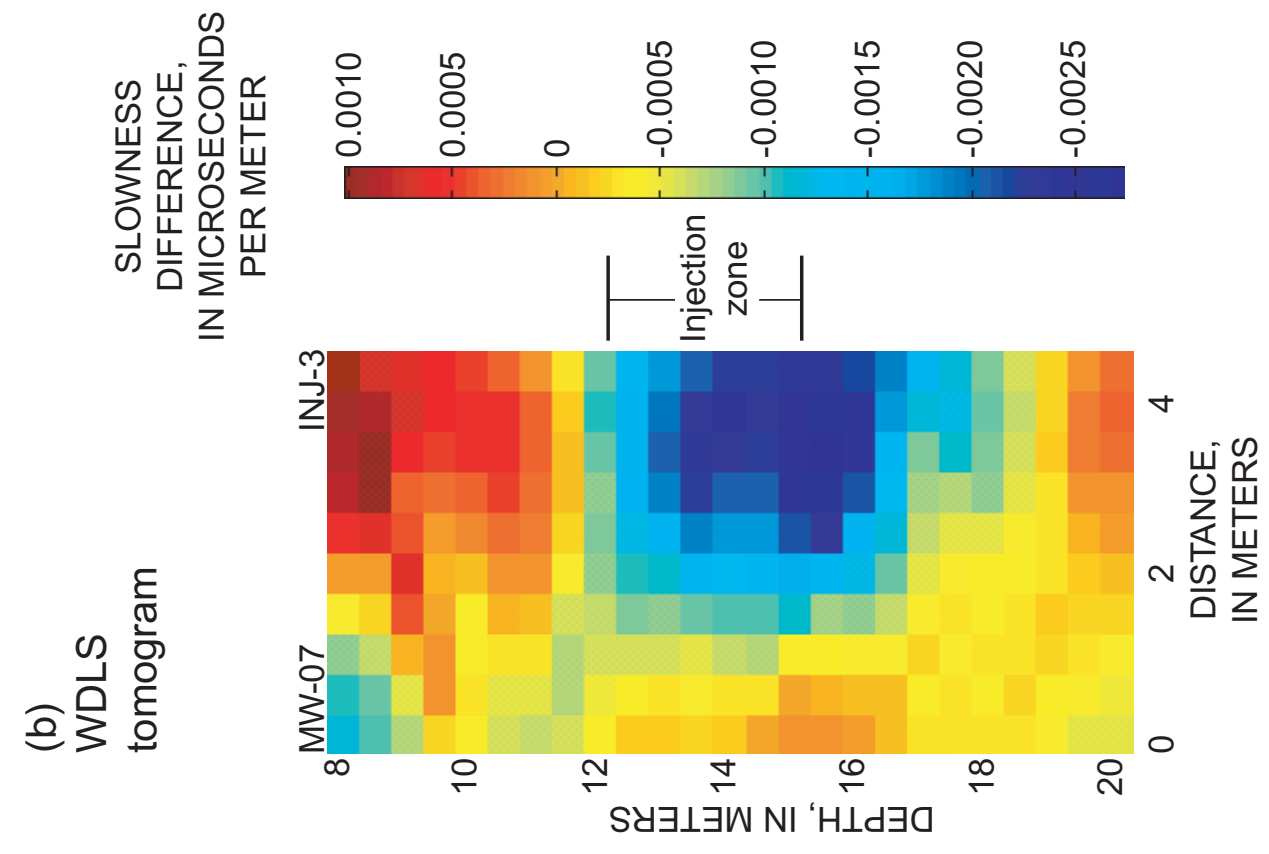

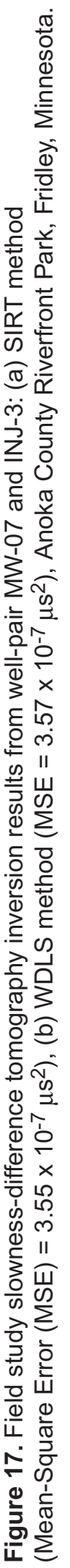


synthetic modeling results, some streaking of the anomaly parallel to the high-angle rays can be observed, and positive slowness-difference increases are present above and below the injection zone. The maximum magnitude of the injection-zone anomaly is $-0.0025 \mu \mathrm{s} / \mathrm{m}$.

In both the SIRT and WDLS tomograms, the slowness-difference anomaly extends from the top of the injection well zone screen (at $12.2 \mathrm{~m} \mathrm{bgs}$ ) to $18 \mathrm{~m}$, which is about $3 \mathrm{~m}$ below the bottom of the injection zone well screen. Because the emulsion is less dense than water, the presence of oil below the well screen indicates the presence of heterogeneity. Higher sediment permeability below the injection well screen than above the well screen might divert the injectate in this manner.

\section{Field Experiment: Results of Object-Based Inversion}

The field data were inverted using OBI with a starting model based on the general shape and magnitude of the anomaly present in the WDLS tomogram (fig. 18a). The OBI tomogram is shown in figure $18 \mathrm{~b}$. OBI parameter estimates are provided in table 1.

Table 1. Object-based inversion starting model parameters and field-data inversion results using starting model based on WDLS tomogram

Tomography image plane extends 5 meters horizontally and 13 meters vertically

Inversion for vertical extent of anomaly

\begin{tabular}{lcc}
\hline & \multicolumn{2}{c}{ Vertical location } \\
& \multicolumn{2}{c}{ (meters below ground surface) } \\
\cline { 2 - 3 } & Starting model & Inversion \\
\hline Anomaly top & 12 & 11.71 \\
Anomaly bottom & 18 & 18.37 \\
\hline
\end{tabular}

Inversion for horizontal extent and slowness of layers

\begin{tabular}{|c|c|c|c|c|c|c|}
\hline \multirow{2}{*}{$\begin{array}{l}\text { Layer } \\
\text { number }\end{array}$} & \multicolumn{2}{|c|}{$\begin{array}{c}\text { Layer minimum extent } \\
\text { (meters) }\end{array}$} & \multicolumn{2}{|c|}{$\begin{array}{c}\text { Layer maximum extent } \\
\text { (meters) }\end{array}$} & \multicolumn{2}{|c|}{$\begin{array}{c}\text { Slowness difference } \\
\text { (microseconds per meter) }\end{array}$} \\
\hline & $\begin{array}{c}\text { Starting } \\
\text { model }\end{array}$ & Inversion & Starting model & Inversion & $\begin{array}{c}\text { Starting } \\
\text { model }\end{array}$ & Inversion \\
\hline 1 & 1.0 & 1.42 & 4.4 & 4.36 & -0.00120 & -0.00158 \\
\hline 2 & 1.0 & 1.37 & 4.4 & 4.38 & -0.00170 & -0.00215 \\
\hline 3 & 1.5 & 1.76 & 4.4 & 4.26 & -0.00200 & -0.00237 \\
\hline 4 & 2.5 & 2.40 & 4.4 & 3.88 & -0.00130 & -0.00182 \\
\hline
\end{tabular}

The vertical distribution and shape of the OBI slowness-difference anomaly (fig. 18b) resembles the anomaly in the WDLS tomogram (fig. 17b). The radial extent of the anomaly increases from the bottom to the top of the tomogram. Slowness difference estimates from OBI are about $30 \%$ higher than WDLS estimates. OBI mean square error estimates $\left(\sim 9.2 \times 10^{-7} \mu \mathrm{s}^{2}\right)$ are higher than for SIRT or WDLS $\left(\sim 3.6 \times 10^{-7} \mu \mathrm{s}^{2}\right)$. As observed in the SIRT and WDLS tomograms, the OBI tomogram contains a slowness-difference anomaly that extends about three meters below the well screen, indicating injectate-penetrated sediments well below the screen bottom.

\section{Estimation of Vegetable-Oil Emulsion Sediment Saturation and Volume}

One goal of the crosswell radar tomography is to estimate the degree of pore-fluid displacement resulting from injection of the vegetable-oil emulsion. We solve a three-phase 

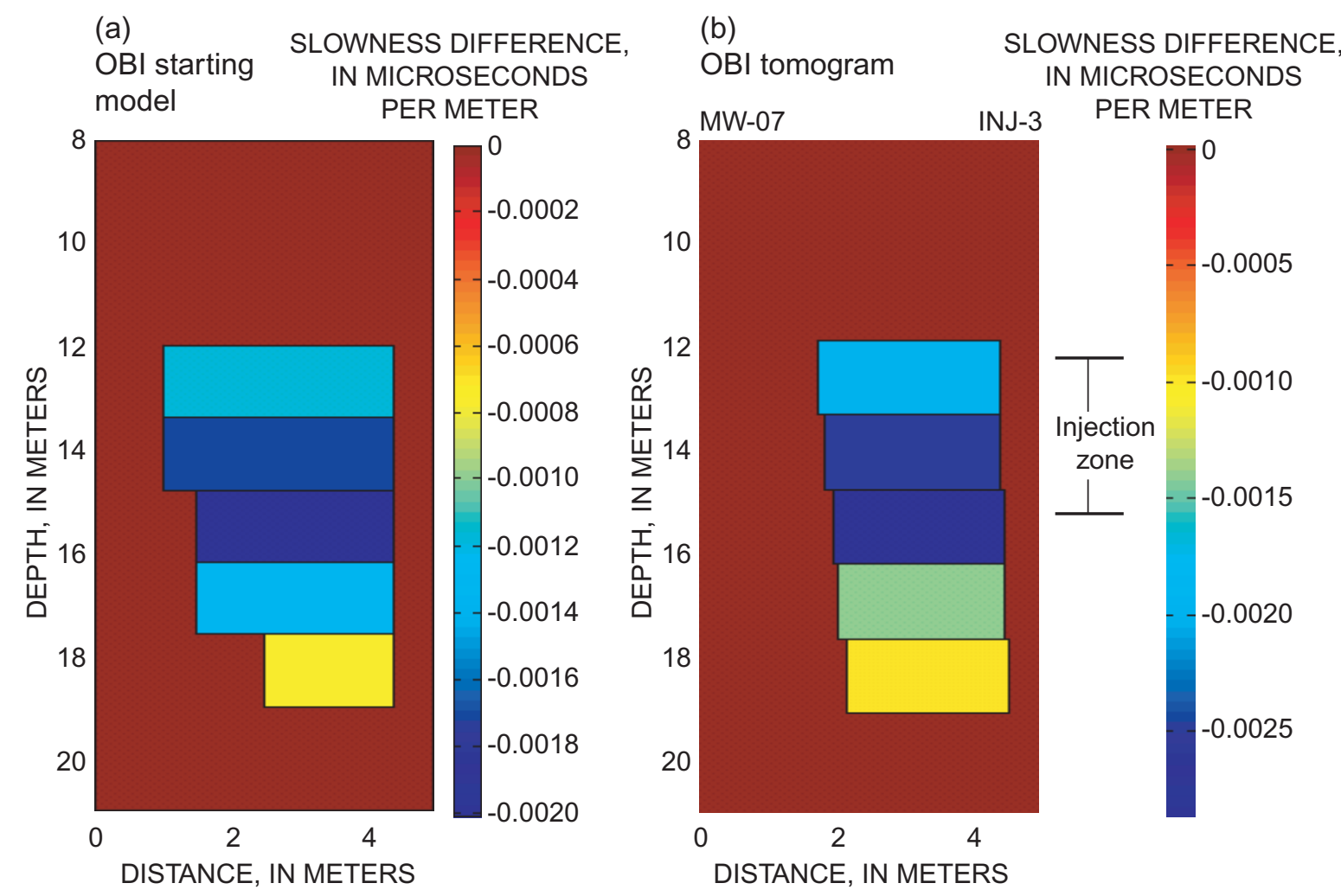

Figure 18. Field study slowness-difference tomography inversion results from well-pair MW-07 and INJ-3 using the object-based inversion (OBI) method (a) the OBI starting model based on the WDLS tomogram (fig.17b), (b) OBI tomogram (Mean-Square Error (MSE) $=7.55 \times 10^{-7} \mu \mathrm{s}^{2}$ ), Anoka County Riverfront Park, Fridley, Minnesota. 
version of the CRIM formula (Birchak and others, 1974; Wharton and others, 1980) for vegetable-oil emulsion saturation assuming electrical conductivity effects are negligible and EM wave propagation velocity is controlled by the real components of the relative dielectric permittivity of the matrix, water, and vegetable-oil emulsion. Assuming matrix porosity is known or can be estimated from other information (such as cores, neutron logs, or petrophysical analysis of pre-injection EM-wave velocity), the vegetable-oil emulsion saturation can be estimated from inverted slowness-difference by:

$$
S^{V O E}=\frac{\Delta s c}{\phi\left(\sqrt{\varepsilon_{r}^{V O E}}-\sqrt{\varepsilon_{r}^{H_{2} O}}\right)}
$$

where,

$S^{V O E}$ is vegetable-oil emulsion saturation (dimensionless);

$\Delta s$ is the slowness difference $(\mu \mathrm{s} / \mathrm{m})$;

$c$ is the speed of light $(299.79 \mathrm{~m} / \mu \mathrm{s})$;

$\phi$ is matrix porosity (dimensionless);

$\varepsilon_{r}^{V O E}$ is relative permittivity of the vegetable-oil emulsion (dimensionless); and,

$\varepsilon_{r}^{H_{2} O}$ is the relative permittivity of water (dimensionless).

Neutron logs collected at the field site indicate sediment porosity ranges between 28 and $34 \%$, with an average of $31 \%$. Table 2 shows average neutron log porosity over the OBI anomaly interval. Using equation (10) and a porosity of $31 \%$, we estimate vegetable-oil emulsion saturation in the injection zone ranges from about 60 to almost $90 \%$ (table 2).

Table 2. Estimation of vegetable-oil emulsion saturation [OBI - object-based inversion]

\begin{tabular}{cccccc}
\hline $\begin{array}{c}\text { Layer } \\
\text { number }\end{array}$ & $\begin{array}{c}\text { OBI inverted slowness } \\
\text { difference } \\
\text { (microseconds per meter) }\end{array}$ & $\begin{array}{c}\text { Layer radius } \\
\text { (meters) }\end{array}$ & $\begin{array}{c}\text { Layer thickness } \\
\text { (meters) }\end{array}$ & $\begin{array}{c}\text { Mean neutron } \\
\text { log porosity }\end{array}$ & $\begin{array}{c}\text { Estimated } \\
\text { saturation } \\
\text { (percent) }\end{array}$ \\
\hline 1 & -0.00158 & 2.95 & 1.7 & 0.31 & 59 \\
2 & -0.00215 & 3.02 & 1.7 & 0.31 & 81 \\
3 & -0.00237 & 2.50 & 1.7 & 0.31 & 89 \\
4 & -0.00182 & 1.48 & 1.7 & 0.31 & 68 \\
\hline
\end{tabular}

The accuracy of the emulsion saturation estimates in table 2 is difficult to assess without additional supporting information. Vegetable-oil emulsion pore-fluid displacement is affected many factors such as the physical properties of the emulsion, well screen injection dynamics, and physical and hydrologic conditions of the aquifer from the pore- to meter-scale. As the distance from the well screen increases, one would expect the upper bound on emulsion saturation to be much less that $100 \%$. There are numerous potential sources of error associated with the experimental, inversion, and analytical procedures we used to estimate emulsion saturation; further work is needed to determine if our estimates of emulsion saturation are reasonable. 
The results of the field experiment demonstrate that crosswell radar slowness-difference tomography methods can be used to image subsurface vegetable-oil injections and provide preliminary evidence that the method can be used to estimate variables of interest to hydrologists and engineers engaged in vegetable-oil biostimulation projects.

\section{Summary}

Through synthetic modeling and analysis of field experimental data, it is shown that crosswell radar difference travel-time tomography provides a means to monitor the emplacement of vegetable-oil emulsion for biostimulation. Our results also illustrate what has been shown in previous investigations: pixel-based inversion methods (such as SIRT and WDLS) may produce tomograms containing artifacts that complicate or preclude quantitative interpretation of tomograms using petrophysical models. In synthetic examples, the pixel-based inversion methods produced tomograms in which (1) anomaly localization is poor and the target anomaly is spread laterally across the interwell region; (2) spurious streaks appear parallel to high-angle raypaths; and (3) anomaly magnitude is underestimated, rendering subsequent petrophysical analysis problematic. In contrast, using an appropriate starting model, the OBI methodology accurately estimated target anomaly location, extent, and magnitude. Inversion mean square error using OBI can be greater than for the pixel-based methods because there are far fewer parameters to fit to the data; however, based on synthetic examples, we expect the OBI results to be more reliable and more appropriate for subsequent petrophysical analysis.

We presented both pixel-based and object-based inversions of crosswell radar travel-time field data from a U.S. Navy pilot-scale vegetable-oil biostimulation project underway at Anoka County Riverfront Park, located down gradient of the Naval Industrial Reserve Ordnance Plant, in Fridley, Minnesota. Both pixel-based and OBI slowness-difference tomograms contain slowness-difference anomalies accompanying vegetable-oil injection. As in the synthetic examples, tomograms generated using pixel-based inversion were subject to streaking and blurring. The tomograms calculated using OBI identify clearly the boundary of the region affected by injection and produce an estimate of anomaly radial extent and magnitude readily interpreted in the context of conceptual (or, ultimately numerical) models of flow and transport.

Based on the OBI-derived difference-slowness tomograms, porosity estimates from neutron logs, and a petrophysical model based on the three-phase CRIM formula, we estimated that vegetable-oil emulsion saturation in the injection zone ranges from about 60 to $90 \%$. Further work is needed to assess the accuracy of emulsion saturation estimates and to identify the magnitude of errors affecting the inversion and analysis process. 


\section{Acknowledgments}

This project was supported by Southern Division Naval Facilities Engineering Command under MIPRs N6246701MP01929 and N6246702MP02932, and by the U.S. Geological Survey Toxic Substances Hydrology Program. The authors acknowledge the assistance of B. Venky Venkatesh and Samuel Tate Jr. and the expert field assistance provided by Peter Joesten, Chris Kochiss, and Eric White.

\section{References}

1. Binley, A., P. Winship, R. Middleton, M. Pokar, and J. West, 2001, High resolution characterization of unsaturated zone dynamics using cross-borehole radar: Water Resources Research, v. 37, no. 11, p. 2639-2652.

2. Birchak, J.R., Gardner, C.G., Hipp, J.E., and Victor, J.M., 1974, High dielectric constant microwave probes for sensing soil moisture: Proc. IEEE, v. 62, p 93-98.

3. Censor, Y., 1983, Finite series-expansion reconstruction methods: Proc. IEEE, v. 71, n. 3, p. $409-419$.

4. CH2M Hill Constructors, Inc., 2002, Pilot-scale study to enhance in-situ bioremediation of chlorinated solvents via vegetable oil injection at Anoka County Riverfront Park, Naval Industrial Reserve Ordnance Plant Fridley, Fridley, Minnesota: Atlanta, Georgia, CH2M Hill Constructors, Inc., CD ROM.

5. Coleman, T.F., and Li, Y, 1994, On the convergence of reflective Newton methods for largescale nonlinear minimization subject to bounds: Mathematical Programming, v. 67, no. 2, p. $189-224$.

6. Coleman, T.F., and Li, Y., 1996, An interior, trust region approach for nonlinear minimization subject to bounds: SIAM Journal on Optimization, v. 6, p. 418-445.

7. Day-Lewis, F. D., Harris, J.M., and Gorelick, S.M., 2002, Time-lapse inversion of crosswell radar data: Geophysics, v. 67, no. 6, p. 1740-1752.

8. Day-Lewis, F. D., Lane, J. W., Jr., Harris, J.M., and Gorelick, S.M., in review, Dynamic imaging of saline tracer tests using cross-borehole radar tomography: Water Resources Research.

9. Dines, K. A., and Lytle, R.J., 1979, Computerized geophysical tomography: Proc. IEEE, v. 67, p. $1065-1073$.

10. Frederickson, J. K., Brockman, F. J., Streile, G. P., Cary, J. W., and McBride, J.F., 1993, Enhancement of in-situ microbial remediation of aquifers: US Patent number US 5,265,674/A/, Patent and trademark office, Box 9, Washington, DC 20232. 
11. Hubbard, S., Chen, J., Peterson, J., Majer, E., Williams, K., Swift, D., Mailliox, B., and Rubin, Y., 2001, Hydrogeological characterization of the D.O.E. bacterial transport site in Oyster Virginia using geophysical data: Water Resour. Res , v. 37, no. 10, p. 24312456.

12. Hutter, J.C., Vandegrift, G.F., Nunez, L., and Redfield, D.H., 1994, Removal of VOCs from groundwater using membrane-assisted solvent extraction: AICHE Journal, v. 40, no. 1, p. 166-177.

13. Ivansson, S., 1984, Crosshole investigations--tomography and its application to crosshole seismic measurements: Stockholm, Sweden, Srtipa Project, SKB, IR-84-08.

14. Kong, F., Westerdahl, H., and Kitterod, T.L., 1994, Radar tomography from environmental geotechnology--field and simulation tests, in : International Conference of Ground Penetrating Radar, 5 ${ }^{\text {th }}$, June 12-16, 1994, Kitchener, Ontario, Proceedings: Waterloo, Canada, Waterloo Centre for Groundwater Research, p. 1249-1260.

15. Lane, J.W., Jr., Day-Lewis, F.D., Harris, J.M., Haeni, F.P., and Gorelick, S.M., 2000, Attenuation-difference radar tomography--results of a multiple-plane experiment at the U.S. Geological Survey Fractured Rock Research Site, Mirror Lake, New Hampshire, in Noon, D.A., Stickley, G.F., and Longstaff, D., eds., International Conference on Ground Penetrating Radar, $8^{\text {th }}$, Proceedings: University of Queensland, Queensland, Australia, p. 666-675.

16. Lane, J.W., Jr., Haeni, F.P., and Day-Lewis, F.D., 1998, Use of time-lapse attenuationdifference radar tomography methods to monitor saline tracer transport in fractured crystalline bedrock, in International Conference on Ground Penetrating Radar, $7^{\text {th }}$, May 27-30, Lawrence, Kansas, 1998, Proceedings: Lawrence, Kansas, University of Kansas, p. 533-538.

17. Lane, J.W., Jr., Haeni, F.P., Placzek, Gary, and Wright, D.L., 1996, Use of borehole-radar methods to detect a saline tracer in fractured crystalline bedrock at Mirror Lake, Grafton County, New Hampshire, in International Conference on Ground-Penetrating Radar (GPR'96), $6^{\text {th }}$, September 30-October 3, 1996, Sendai, Japan, Proceedings: Sendai, Japan, Tohoku University Department of Geoscience and Technology, p. 185-190

18. McMechan, G.A., 1983, Seismic tomography in boreholes: Geophysical Journal of the Royal Astronomical Society, v. 74, p. 601-612.

19. McMechan, G.A., Harris, J.M., and Anderson, L.M., 1987, Cross-hole tomography for strongly variable media with applications to scale model data: Bull. Seismol. Soc. Am., v. 77 , no. 6 , p. 1945-1960.

20. Menke, W., 1984, The resolving power of cross-borehole tomography: Geophysical Research Letters, v. 11, p. 105-108.

21. Menke, W., 1989, Geophysical data analysis--discrete inverse theory (revised ed.): San Diego, Academic Press.

22. Niva, B., Olsson, O., and Blumping, P., 1988, Radar cross-hole tomography at the Grimsel Rock Laboratory with application to migration of saline tracer through fracture zones: Nationale Genossenschaft fur die lagerung radioaktiver Abfalle, NTB 88-31. 
23. Olsson, O., Falk, L., Forslund, O., Lundmark, L., and Sandberg, E., 1992, Borehole radar applied to the characterization of hydraulically conductive fracture zones in crystalline rock: Geophysical Prospecting, v. 40, no. 2, p. 109-142.

24. Peterson, J.E., Paulsson, B.J.P., and McEvilly, T.V., 1985, Applications of algebraic reconstruction techniques to crosshole seismic data: Geophysics, v. 50. no. 10, p. 15661580.

25. Ramirez, A.L., and Lytle, R.J., 1986, Investigation of fracture flow paths using alterant geophysical tomography: J. Rock Mech Min. Sci. Geomech., v. 23, p. 165-169.

26. Schuster, G.T., 1995, Fracture resolution limits for crosswell migration and traveltime tomography--theory, in SEGJ/ SEG International Symposium, $3^{\text {rd }}$, Proceedings: p. 86-93.

27. Stewart, R.R., 1992, Exploration seismic tomography--fundamentals, in Domenico, S.N., ed., Course Notes Series, Volume 3: Tulsa, Oklahoma, Society of Exploration Geophysicists.

28. Vasco, D.W., Peterson. J.E. Jr., and Majer, E.L., 1995, Beyond ray tomography--wavepaths and Fresnel volumes: Geophysics, v. 60, p. 1790-1804.

29. Wharton, R.P., Hazen, G.A., Rau, R.A., and Best, D.L., 1980, Electromagnetic propagation logging--advances in technique and interpretation: Soc. Petr. Eng., $55^{\text {th }}$ Annual Technical Conference, Paper 9267.

30. Wright, D.L., Grover, T.P., Ellefsen, K.J., Lane, J.W., Jr., and Kase, P.G., 1996, Radar tomograms at Mirror Lake, New Hampshire--3-D visualization and a brine tracer experiment, in Symposium on the Application of Geophysics to Engineering and Environmental Problems (SAGEEP), April 28-May 2, Keystone, Colorado, Proceedings: Wheat Ridge, Colorado, Environmental and Engineering Geophysical Society, p. 565-575.

Citation: Lane, J.W., Jr., Day-Lewis, F.D., Versteeg, R.J., and Casey, C.C., 2003, Object-based inversion of crosswell radar tomography data to monitor vegetable-oil injection experiment, in Symposium on the Application of Geophysics to Engineering and Environmental Problems (SAGEEP), April 6-10, 2003, San Antonio, Texas,Proceedings: Denver, Colorado, Environmental and Engineering Geophysics Society, CD-ROM, 27 p. 